\title{
EFECTO DE LA SEQUÍA EN LA MORFOLOGIA, CRECIMIENTO Y PRODUCTIVIDAD DE GENOTIPOS DE PAPA (SolanUm tuberosum L.) EN BOLIVIA
}

\section{P. Mamani-Rojas'; J. François-Ledent ${ }^{2}$}

\begin{abstract}
Resumen
En las regiones montañosas andinas de Tiraque, Cochabamba, Bolivia y en dos años consecutivos se evaluaron seis variedades de papa contrastantes en su tolerancia a la sequía, en condiciones semi-controladas usando pequeños contenedores apropiados para la siembra y bajo una cubierta tipo tinglado que sirvió de resguardo de la lluvia. El objetivo fue determinar los mecanismos morfológicos utilizados por la papa para adaptase a la sequía e identificar parámetros morfológicos sensibles a la sequía que estén asociados con el rendimiento del cultivo. Se aplicaron tres regímenes de agua: $\mathbf{R 0}=$ riego a capacidad de campo (testigo), R1 = sequía al inicio de la tuberización (sequía temprana) y $\mathbf{R 2}=$ sequía a un mes del inicio de la tuberización (sequía tardía). Se evaluaron parámetros morfológicos, variables de crecimiento, variables de daño y componentes de rendimiento. Se observaron grandes diferencias morfológicas entre variedades y se determino que la sequía temprana tiene un mayor efecto en la morfología de la planta que la sequía tardía. La tipología morfológica de las variedades sensibles y tolerantes muestra diferencias substanciales entre ellas. Se demostró que en la mayoría de las variedades la altura de planta, el número de entrenudos, el número de hojas y el número de ramas fueron las variables morfológicas más afectadas por la sequía temprana. De todas ellas, la susceptibilidad a la sequía del número de ramas está marcadamente asociada a la susceptibilidad del rendimiento de cada variedad. Como
\end{abstract}

\footnotetext{
${ }^{1}$ Investigador ecofisiólogo, suelos y producción agrícola de la Fundación PROINPA, Cochabamba, Bolivia.p.mamani@proinpa.org

${ }^{2}$ Ex Profesor de la Université Catholique de Louvain la neuve, Bélgica
} 
un índice más estricto para elegir material productivo en condiciones de sequía, se estimó el índice de "Susceptibilidad potencial del rendimiento" el cual al estar asociado con la susceptibilidad del número de ramas y del número de hojas, pueden ser usados como indicadores de tolerancia a la sequía. Por otra parte se destaca las características de la variedad Waych'a que difiere de las otras en términos de su mayor velocidad de crecimiento, el aumento de su índice de raíz, su capacidad de recuperación después del riego y el llenado de sus tubérculos pequeños, como mecanismos particulares que las hace menos sensible y con mayor estabilidad en condiciones de sequía.

Palabras claves adicionales:

$$
\begin{aligned}
& \text { Sequía, estrés hídrico, } \\
& \text { morfología, índice de raíz, índice } \\
& \text { de cosecha, índice de daño, } \\
& \text { componentes de rendimiento. }
\end{aligned}
$$

Aceptado para publicación: 25 de febrero, 2014

\section{DROUGHT EFFECT ON THE MORPHOLOGY, GROWTH AND PRODUCTIVITY OF POTATO GENOTYPES (SOlanUm tuberosum L.) IN BOLIVIA}

\section{Summary}

In the Andean highlands of Tiraque, Cochabamba, Bolivia and during two consecutive years, six contrasting potato varieties were evaluated in their tolerance to drought, in semi-controlled conditions using small containers suitable for planting under a cover shed type that served as a shelter from rain. The objective was to determine the morphological mechanisms used by the potato adapt to drought and identify sensitive morphological parameters associated with crop yield. Three water regimes were applied: $\mathbf{R 0}=$ irrigation at field capacity (control), R1 = drought at the tuber initiation (early drought) and R2 = drought to a tuber initiation month (late drought). Morphological parameters were evaluated, growth variables, variables of damage and yield components. 
Large morphological differences were observed between varieties determining that early drought has a greater effect on the morphology of the plant than late drought. The morphological type of sensitive and tolerant varieties shows substantial differences between them. It was shown that in most varieties of plant height, the number of internodes, number of leaves and number of branches were the morphological variables most affected by early drought. Of all these, susceptibility to drought in the number of branches is markedly associated with the yield susceptibility of each variety. As a stricter index to choose productive material under drought conditions, it was estimated the index of "Potential susceptibility of yield" which associated with the susceptibility of branches and leaves number can be used as indicators tolerance to drought. Of these, the sensitivity of number of branches is strongly associated to the performance sensitivity, therefore, this variable can be used as an indicator of drought tolerance in potato. Moreover, it highlights the characteristics of the variety Waych'a that differs from the others in terms of its higher growth rate, increase of root rate, its capacity of recuperating after irrigation and filling their small tubers, as particular mechanisms which make it less sensitive and with more stability in drought conditions.

Additional keywords:

Drought, water stress, morphology, root index, harvest index, damage index, yield components.

\section{Introducción}

La sequía es uno de los mayores factores abióticos que afectan la producción de papa en las Regiones Andinas de Bolivia, limitando el rendimiento y la calidad del tubérculo. En los últimos tiempos por efecto del cambio climático se han acortado los periodos de lluvias y la ocurrencia de sequías en periodos clave del desarrollo de los cultivos es cada vez más frecuente (Jensen, 2010; Coppock y Valdivia, 2001; Staubi, et al, 2008). El cultivo de papa es conocido por su susceptibilidad a la escasez 
de agua y se han observado diferencias genotípicas en su tolerancia a la sequía (Tourneux, et al. 2003). El rendimiento de este cultivo depende de la duración y de la intensidad del estrés hídrico, del clima y de las condiciones del suelo (Calispa, 2000).

En la región Andina de Bolivia la papa es el principal cultivo y permite la alimentación de más de 240,000 familias con una producción total estimada en más de 800.000 toneladas, una superficie cultivada de más de 120.000 hectáreas. Es cultivada principalmente en las regiones montañosas, sobre los 3.000 msnm donde los rendimientos se encuentran entre 6 t.ha ${ }^{-1}$ (Zeballos, et al. 2009). Alrededor de 228 variedades de papa son cultivadas en Bolivia correspondientes a ocho especies de papa (Solanum ajanhuiri, S. goniocalyx, S. stenotonum, $S$. chaucha, S. Juzepczukii, S. curtilobum y $S$. tuberosum ssp. tuberosum y ssp. andigena), (Alarcón 1976).

El conocimiento de los mecanismos de la planta que están asociados con la productividad de los genotipos de papa en condiciones de sequía, permitirá establecer una tipología de variedades y especies tolerantes a la sequía en las condiciones de Bolivia. Además, la comprensión de estos mecanismos permitirá identificar variables asociadas con la productividad del cultivo en condiciones de este tipo de estrés. Es por esto que el objetivo de este estudio fue determinar los mecanismos morfológicos utilizados por la planta de papa para adaptase a la sequía e identificar parámetros morfológicos sensibles asociados con el rendimiento del cultivo. Estos parámetros podrían usarse para la elección de material progenitor con tolerancia a la sequía.

Según Tourneux, et al (2003), muchos caracteres fisiológicos de la planta de papa (como la resistencia de los estomas, fotosíntesis, contenido de agua de la hoja y el potencial hídrico de la hoja) y morfológicos o caracteres agronómicos (como índice de área foliar, senescencia foliar, cobertura vegetal, producción de materia seca, partición de asimilatos a los tubérculos y componentes del rendimiento) son afectados por la falta de agua y podrían ser utilizados como indicadores de los efectos de la sequía en la producción de papa. En la región 
andina de Bolivia, hay poca información disponible acerca del comportamiento morfológico y fisiológico de genotipos de papas nativas cultivadas en condiciones de sequía (PROINPA, 1994).

\section{Materiales y Métodos}

El estudio se realizó en dos campañas consecutivas en la provincia Tiraque de Cochabamba, Bolivia ubicada a 3540 msnm, 17.4 latitud sur, 65.7 longitud oeste y cuyas temperaturas mínima, máxima y media son de $2,20,11^{\circ} \mathrm{C}$ respectivamente y su precipitación anual de $530 \mathrm{~mm}$. El ensayo del primer año fue planeado para ganar experiencia en los tratamientos hídricos y en el comportamiento de las variedades. Esta experiencia permitió adecuar los tratamientos hídricos y elegir mejor las variedades para el ensayo del segundo año.

En ambos ensayos, el ambiente en el que se realizó el estudio fue una cubierta grande con techo de plástico y paredes laterales descubiertas (tipo tinglado), que permitió un mejor control del agua de riego y no alteró mayormente las otras variables climáticas. Para la siembra se utilizó suelo del lugar, cuyas características generales son: textura franco limosa, estructura granular, bajo contenido de materia orgánica (1\%) y bajo contenido de Nitrógeno y Fósforo. La tierra se dispuso en contenedores de madera de $0.4 \times 0.7 \times 0.9 \mathrm{~m}$ de alto, ancho y largo respectivamente. El número de plantas por contenedor fue de seis distribuidas a lo largo del contenedor en dos filas de a tres. Al momento de la siembra se aplicó fertilizante químico a un nivel de $120-120-80 \mathrm{Kg} / \mathrm{ha}$ de NPK respectivamente.

En ambos casos el diseño estadístico utilizado fue el de Bloques Completos al Azar con un arreglo factorial de $6 \times 3$ (6 variedades y 3 tratamientos hídricos), con cuatro repeticiones, totalizando 72 unidades experimentales (contenedores).

Las variedades utilizadas en el primer año fueron:

- Solanum berthaultii L. , especie silvestre, tardía y resistente a la sequía 
- Jaspe, variedad híbrida, semi tardía y tolerante

- Waych'a, variedad andígena, semi tardía y susceptible

- Desirée, variedad tuberosum, precoz y susceptible

- Ch'aska, variedad andígena, tardía y tolerante

- Yungay, variedad híbrido, tardía y tolerante.

Por su comportamiento atípico en relación a las especies cultivadas y su baja productividad, para el segundo año de estudio se sustituyó la especie Solanum berthaultii L., por la especie Solanum jusepzukii, Buk., más conocida como Luk'y que es una variedad amarga que se caracteriza por ser tardía y resistente a la sequía. El resto de las variedades se mantuvo para su evaluación en el segundo año.

El criterio para definir los tratamientos hídricos del primer ensayo fue mantener períodos de sequía que se ajusten a alguna característica del cultivo que se pueda determinar de manera práctica, como el inicio de la tuberización. Estos tratamientos fueron:

R0 = Riego normal a capacidad de campo (testigo)

R1 = Sequía al inicio de la tuberización de cada variedad (sequía temprana)

R2 = Sequía a un mes luego del inicio de la tuberización de cada variedad (sequía tardía)

Como es lógico entender, el inicio de la sequía R1 y R2 para una y otra variedad fue diferente porque el inicio de tuberización entre ellas fue diferente. En el caso de la especie $S$. berthaultii, que tuvo un inicio de tuberización muy tardía, se consideró un inicio de sequía para R1 y R2 similar al de Waych'a por ser la variedad más conocida.

Se trató de mantener una duración de la sequía R1 similar para todas las variedades, es decir 35 días de suspensión completa del riego salvo un riego ligero a los 21 dias. La duración de la sequía R2 no se pudo ajustar a una duración similar a la de R1 debido a que algunas variedades presentaban una mayor susceptibilidad a la sequía producto de su mayor estado de desarrollo. Este aspecto indujo a ajustar la duración de la 
sequía R2, en función del estado del follaje que presentaba cada variedad para lo cual se realizaba observaciones diarias de la sintomatología de la planta. El riego de recuperación en $\mathrm{R} 2$ se realizó antes que la planta ingrese en un estado de marchitez total (ver cuadro 1).

Debido a la gran variabilidad en el inicio de tuberización entre las variedades, en el segundo ensayo el inicio y duración de los tratamientos de sequía se ajustaron a uno solo (Cuadro 1), vale decir al inicio de tuberización de la variedad Waych'a por ser la más conocida.

Los tratamientos de sequía del segundo ensayo fueron:

$\mathrm{R} 0=$ Riego normal a capacidad de campo (testigo)

$\mathrm{R} 1$ = Sequía temprana (Suspensión del riego al inicio de la tuberización de la variedad testigo Waych'a)

$\mathrm{R} 2$ = Sequía tardía (Suspensión del riego a un mes luego del inicio de la tuberización de la variedad testigo Waych'a)

En ambos ensayos los riegos se aplicaron con una frecuencia de dos veces por semana, en volúmenes que variaron de acuerdo al contenido de humedad en el suelo, el cual fue evaluado en forma gravimétrica (Piñas, 2012).

La siguiente relación permitió determinar los volúmenes de agua de riego:

$$
V=[(C C-H a) / 100] \times D a \times P \times A
$$

\section{Donde:}

$\mathrm{CC}=$ capacidad de campo $=17 \%$

$\mathrm{Ha}=$ humedad actual del suelo determinado gravimétricamente dos veces por semana

$\mathrm{Da}=$ densidad aparente del suelo $=1300 \mathrm{Kg} / \mathrm{m}^{3}$

$\mathrm{P}=$ profundidad del suelo $=$ de 0.2 a $0.4 \mathrm{~m}$ (según el crecimiento de la raíz).

$A=$ área a regar en las cajas $=0.7 \mathrm{~m} \times 0.9 \mathrm{~m}=0.63 \mathrm{~m}^{2}$

Las variables morfológicas que se estudiaron en el ensayo del primer año y que se evaluaron al inicio y al final de los períodos 
de sequía en dos plantas centrales de cada unidad experimental, fueron la altura de la planta y las características del tallo principal que se consideraban que podían estar asociados con la sequía como el número de hojas, número de entrenudos, número de ramas y algunas características de la hoja del penúltimo entrenudo (Figura 1). La altura de planta se midió desde el suelo hasta el punto de inserción de la última hoja apical del tallo principal, manteniéndolo en forma vertical. Los entrenudos se reconocieron en base a la apreciación visual de los nudos donde normalmente se insertan las hojas. Se seleccionó como tallo principal el más vigoroso en términos de longitud y grosor.

Fig. 1. Variables evaluadas en el tallo principal: A) número de ramas, número de hojas, número de entrenudos, longitud del penúltimo entrenudo y B) hoja del penúltimo entrenudo del tallo principal: a) longitud de hoja, b) longitud del raquis y c) longitud del peciolo.
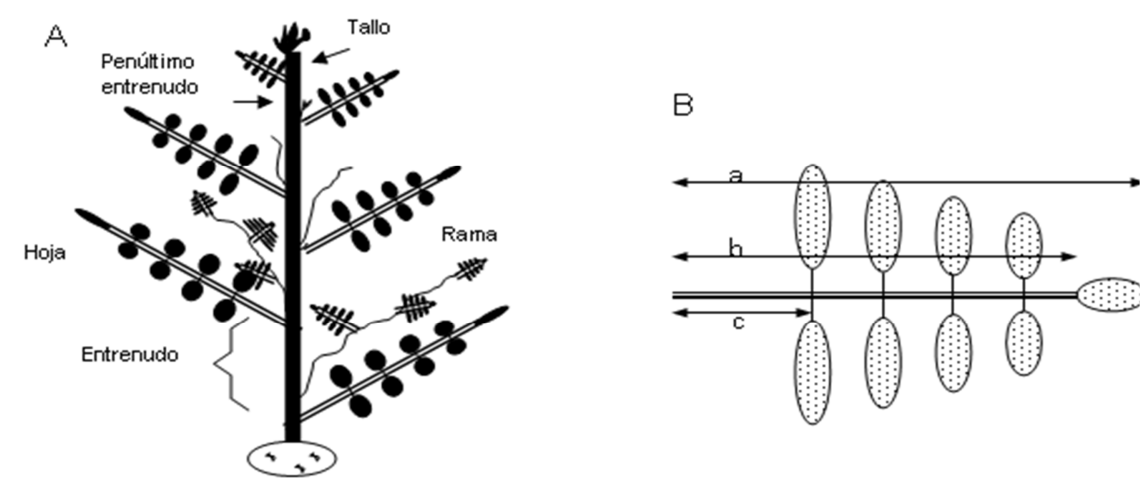

En el ensayo del segundo año, además de evaluar la altura de planta, el número de ramas, el número de hojas y el número de entrenudos tal como se describió para el primer ensayo (Figura $1 \mathrm{~A})$, también se evaluó el índice de daño de la sequía en hojas y tallos para lo cual se utilizó una escala de daño descrita en el Cuadro 2. Esta evaluación se la realizó semanalmente en forma visual durante la duración de la sequía temprana R1. 
Cuadro 1. Inicio y duración de los tratamientos de sequía en el primer y segundo ensayo.

\section{Primer ensayo}

\begin{tabular}{|l|cc|cc|}
\hline \multirow{2}{*}{ Variedad } & \multicolumn{2}{|c}{ R1 } & \multicolumn{2}{c|}{ R2 } \\
& Inicio & Duración & Inicio & Duración \\
\hline S. berth. & 54 & 35 & 82 & 21 \\
Jaspe & 34 & 35 & 62 & 17 \\
Waych'a & 54 & 35 & 82 & 11 \\
Desirée & 25 & 35 & 53 & 19 \\
Ch'aska & 49 & 35 & 78 & 21 \\
Yungay & 43 & 35 & 71 & 21 \\
\hline
\end{tabular}

$\mathrm{R} 1$ = Sequía al inicio de la tuberización de cada variedad

$\mathrm{R} 2$ = Sequía a un mes del inicio de la tuberización de cada variedad

El inicio corresponde a los días después de la siembra.

La duración esta expresado en días.

\section{Segundo ensayo}

\begin{tabular}{|l|cc|cc|}
\hline \multirow{2}{*}{ Variedad } & \multicolumn{2}{|c}{ R1 } & \multicolumn{2}{c|}{ R2 } \\
& Inicio & Duración & Inicio & Duración \\
\hline Luk'y & 55 & 27 & 82 & 15 \\
Jaspe & 55 & 27 & 82 & 15 \\
Waych'a & 55 & 27 & 82 & 15 \\
Desirée & 55 & 27 & 82 & 15 \\
Ch'aska & 55 & 27 & 82 & 15 \\
Yungay & 55 & 27 & 82 & 15 \\
\hline
\end{tabular}

$\mathrm{R} 1$ = Sequía temprana

R2 = Sequía tardía 
Cuadro 2. Escala de daño de la sequía en hojas y tallos. Segundo ensayo.

\begin{tabular}{|l|l|}
\hline \multicolumn{1}{|c|}{ Hojas } & \multicolumn{1}{c|}{ Tallos } \\
\hline 1 = hojas expandidas y turgentes & $1=$ tallos erectos y turgentes \\
$2=$ hojas poco inclinadas y turgentes & $2=$ tallos erectos y poco turgentes \\
$3=$ hojas poco inclinadas y poco turgentes & $3=$ tallos inclinados y poco flácidos \\
$4=$ hojas inclinadas y poco flácidas & $4=$ tallos postrados y flácidos. \\
$5=$ hojas inclinadas y flácidas & \\
$6=$ hojas inclinadas, flácidas y arrugadas & \\
\hline
\end{tabular}


En ambos ensayos antes de la cosecha también se evaluó la materia seca del follaje y de los tubérculos para estimar el Índice de Cosecha (IC) en base a la siguiente relación: IC = materia seca tubérculos / materia seca total.

En el segundo ensayo también se evaluó la materia seca de la raíz para calcular el índice de Raíz (IR) en base a la siguiente relación: $\mathrm{IR}$ = materia seca raíz / materia seca follaje.

El rendimiento en ambos ensayos se evaluó en las seis plantas de cada unidad experimental. Se midió el peso y el número de los tubérculos según su diámetro $\left(1^{\underline{a}}:>5.5 \mathrm{~cm}, 2^{-a}: 5.5-4.5\right.$ $\mathrm{cm}, 3^{\mathrm{a}}: 4.5-3.5 \mathrm{~cm}, 4^{\mathrm{a}}: 3.5-2.5 \mathrm{~cm}$ y $\left.5^{\mathrm{a}}:<2.5 \mathrm{~cm}\right)$.

\section{Resultados y Discusión}

Altura de planta. En ambos ensayos (Figuras 2 y 3 ) en condiciones de un riego normal (R0), existen diferencias marcadas en la altura de planta entre las variedades estudiadas. En el primer ensayo (Figura 2a) Waych'a, Ch'aska y Yungay alcanzan la mayor altura de planta seguidos de Jaspe, $S$. berthaultii y finalmente Desirée como la de menor altura. En el segundo ensayo la tendencia es similar pero se incluye Luk'y como una variedad con una altura de planta intermedia. En condiciones similares, Tourneux, et al (2003) también encontraron diferencias altamente significativas en la altura de planta de diferentes especies y variedades de papa (Waych'a, Alpha, Clone CIP 382171.10, Ajahuiri, Luk'y y Janko Choquepito). En el primer ensayo (Figura 2) se pudo determinar que la velocidad de crecimiento de la variedad Waych'a es mayor debido a que en menor tiempo alcanza una mayor altura (Figura 4).

La sequía temprana $R 1$ afectó el crecimiento de las plantas. En el primer ensayo (Figura 2a) este efecto para $S$. berthaultii, Jaspe, Waych'a, Desirée, Ch'aska y Yungay fue del 37, 49, 5, 51,39 y $24 \%$ respectivamente y en el segundo ensayo (Figura 3a) el efecto de esta sequía para Luk'y, Jaspe, Waych'a, Desirée, Ch'aska y Yungay fue de 28, 20, 8, 7, 39 y $16 \%$ 
respectivamente. Tourneux, et al (2003) también observaron diferencias significativas en la altura de planta de especies y variedades de papa por efecto de tratamientos hídricos diferenciados.

En el primer ensayo (Figura 2) se observa que el riego de recuperación no logra estimular el crecimiento de las plantas debido a que este ocurre cuando tienen un tiempo avanzado de crecimiento y la mayor parte de las variedades en este momento ya alcanzan su máxima altura. En el segundo ensayo (Figura 3a), en Desirée el efecto de la sequía temprana $\mathrm{R} 1$ fue menor que en el primer ensayo debido a que esta sequía se inició cuando la planta estaba con más edad (ver cuadro 1). En ambos ensayos la variedad Waych'a logró evadir el efecto de la sequía temprana gracias a su mayor velocidad de crecimiento.

En el primer ensayo (Figura $2 b$ ) la sequía tardía R2 solo afectó la altura de planta de las variedades Jaspe y Desirée en un 14 y $34 \%$ respectivamente. Las otras variedades cuando se inicio la R2 ya lograron alcanzar su máxima altura de planta. En el segundo ensayo (Figura $3 b$ ), el efecto de esta sequía no fue perceptible en ninguna variedad debido a que cuando esta sequía se inició (82 dds) las variedades ya alcanzaron su máxima altura.

En base a los resultados de ambos ensayos se puede indicar que la variable altura de planta es afectada por la sequía cuando esta ocurre en etapas iníciales del crecimiento de la planta.

Al respecto, Deblonde y Ledent (2001) han reportado un efecto negativo de la sequía en la altura de planta de papa cuya respuesta depende del genotipo, de la precocidad de la variedad y del momento de ocurrencia de la sequía. 
Fig. 2. Variación de la altura de planta por efecto de la sequía en seis variedades de papa. Resultados del primer ensayo, donde: $\mathbf{R O}=$ Riego normal; R1 = Sequía inicio tuberización y R2 = Sequía a un mes del inicio de la tuberización.

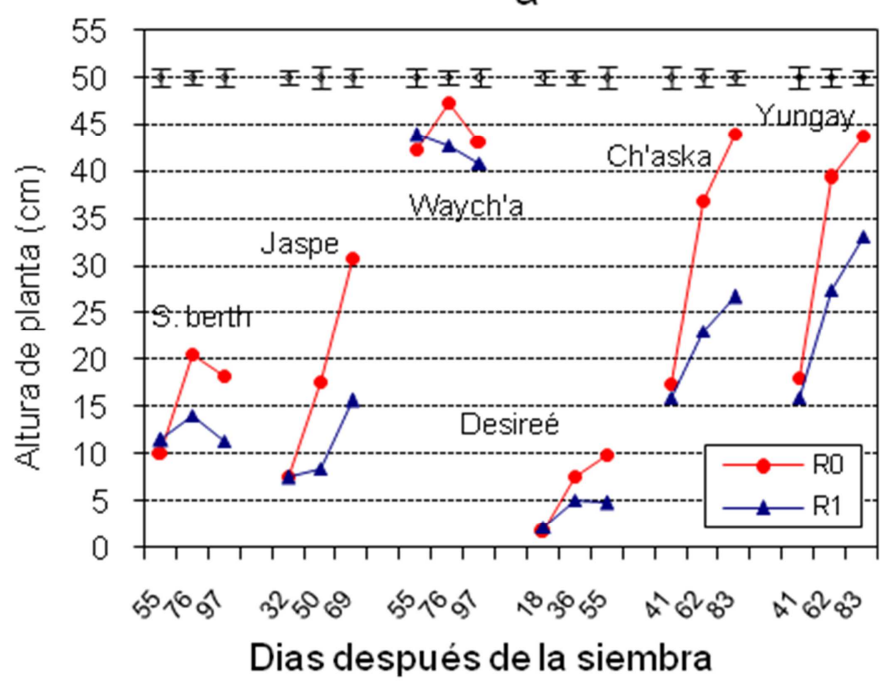

b

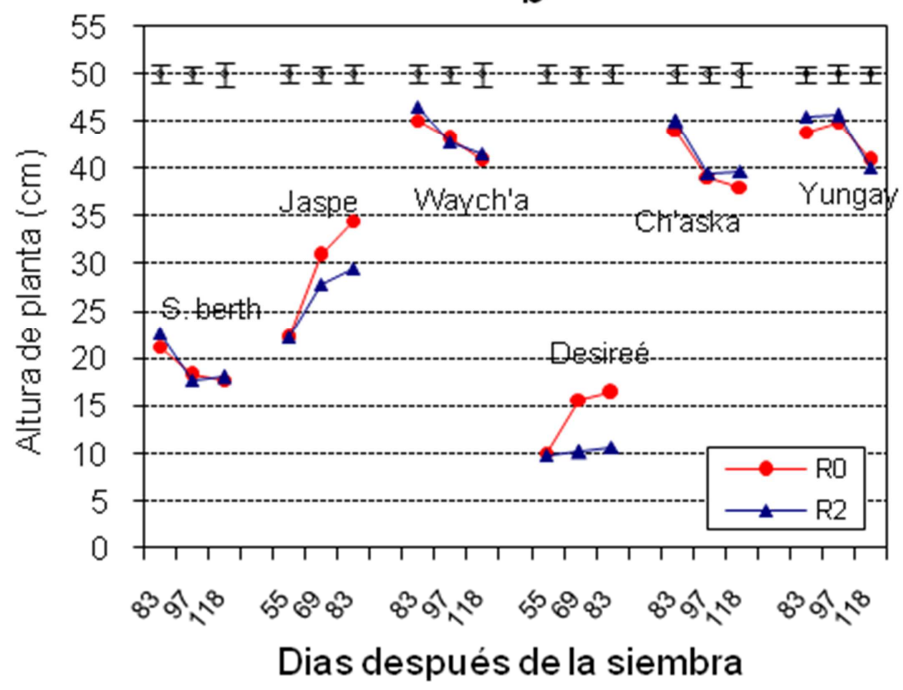


Fig. 3. Variación de la altura de planta por efecto de la sequía en seis variedades de papa. Resultados del segundo ensayo, donde: $\mathrm{RO}=$ Riego normal; R1 = Sequía temprana y R2 = Sequía tardía.
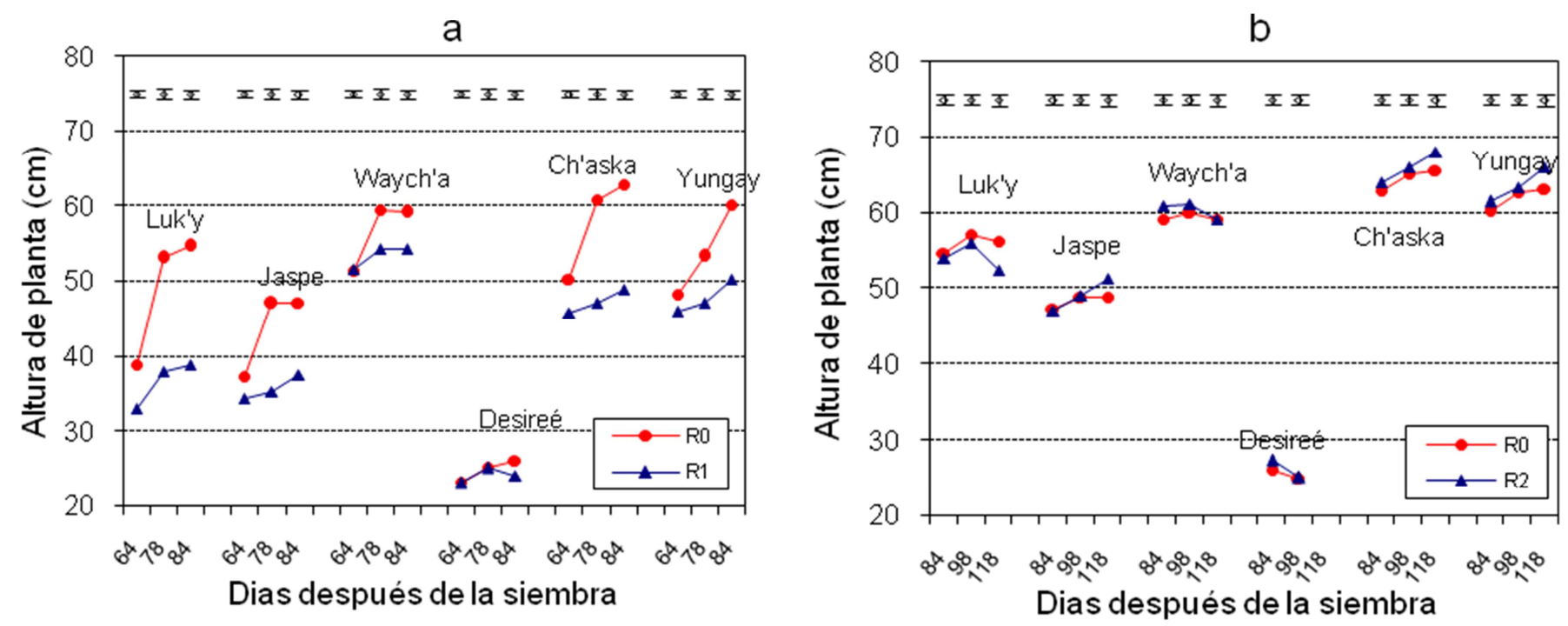
En la Figura 4 se observa la velocidad de crecimiento de variedades de papa en condiciones de riego normal (R0) y sequía temprana (R1). Destaca la variedad Waych'a por alcanzar su máxima altura de planta en menos tiempo en relación a las demás variedades, motivo por el cual su altura de planta no es afectada por la sequía como el del resto de las variedades.

Número de entrenudos. En ambos ensayos (Figuras 5 y 6 ) en condiciones de un riego normal (R0), existen diferencias marcadas en el número de entrenudos entre las variedades estudiadas. En el primer ensayo (Figura 5a) Waych'a y Ch'aska alcanzaron el mayor número de entrenudos seguidos por Yungay, Jaspe y $S$. berthaultii y finalmente Desirée como la de menor número de entrenudos. En el segundo ensayo la tendencia es similar pero se incluye Luk'y como una variedad con bajo número de entrenudos.

El alto número de entrenudos de $S$. berthaultii y su baja altura de planta (Figura 2) muestra que esta especie tiene entrenudos más cortos en relación a las demás variedades, contrariamente el bajo número de entrenudos de Luk'y y su elevada altura de planta (Figura 3) muestra que esta variedad tiene entrenudos más grandes que el resto de las variedades.

La sequía temprana R1 evitó la formación de entrenudos en las plantas. En el primer ensayo (Figura $5 a$ ) este efecto para $S$. berthaultii, Jaspe, Waych'a, Desirée, Ch'aska y Yungay fue del $16,18,9,26,22$ y $7 \%$ respectivamente y en el segundo ensayo (Figura 6a) el efecto de esta sequía para Luk'y, Jaspe, Waych'a, Desirée, Ch'aska y Yungay fue del 5, 8, 7, 0, 16 y 5\% respectivamente.

El efecto de la sequía temprana $\mathrm{R} 1$ en la altura de planta y en el número de entrenudos de algunas variedades muestra que la altura de la planta está relacionada con la formación de nuevos entrenudos. Considerando que el efecto de la R1 fue mayor en la altura de planta que en el número de entrenudos, significa que la elongación de los entrenudos fue afectada. 
Fig. 4. Altura de planta de variedades de papa ajustada a una función polinómica cúbica en condiciones de riego normal ( $R 0)$ y de sequía inicial $(R 1)$.

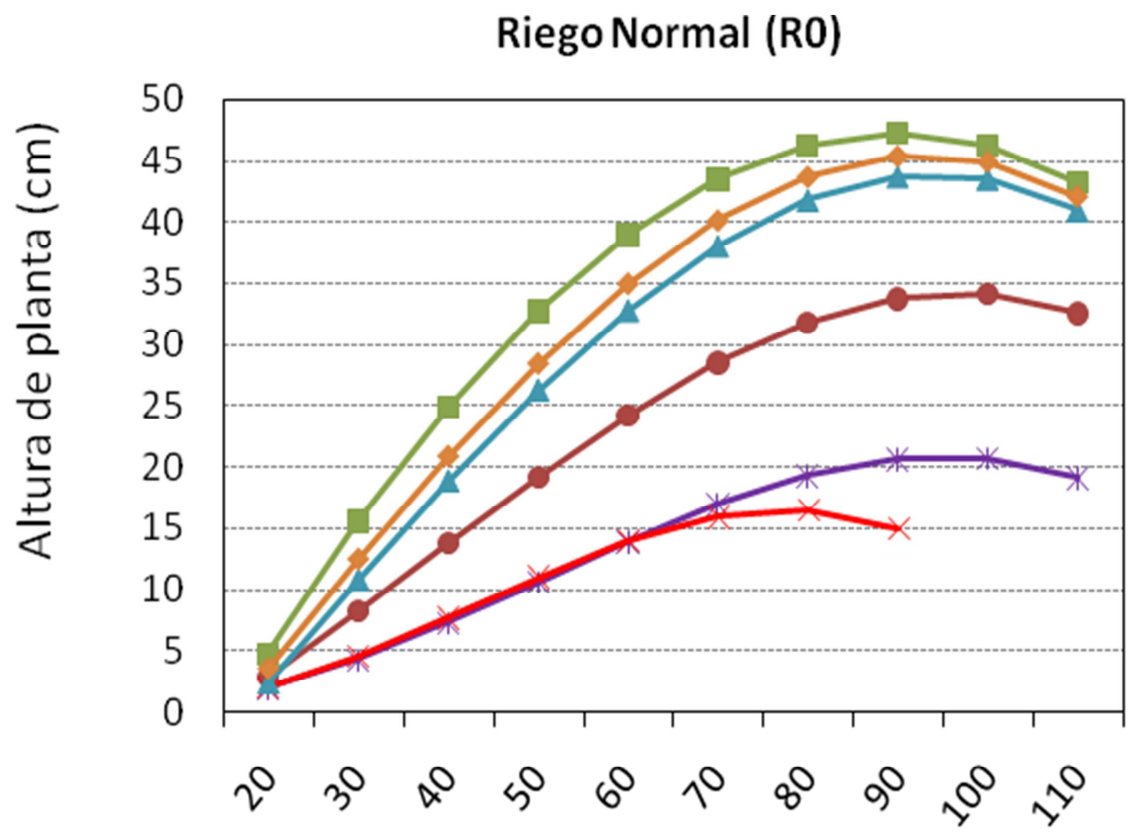

Días después de la siembra

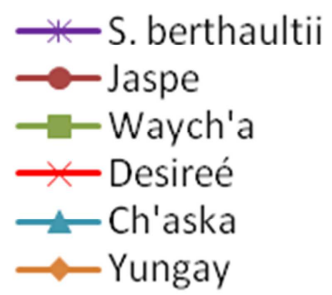

S.berth: $y=-5.4 e^{-5} x^{3}+0.0082 x^{2}-0.0725 x+0.54$ $R^{2}=0.93$

Jaspe: $\quad y=-4.98 e^{-5} x^{3}+0.0054 x^{2}+0.359 x-6.03$ $\mathrm{R}^{2}=0.97$

Waycha: $y=-1.4 e^{-5} x^{3}-0.0059 x^{2}+1.398 x-20.7$ $R^{2}=0.93$

Desireé: $y=-9.09 e^{-5} x^{3}+0.0117 x^{2}-0.167 x+1.48$ $\mathrm{R}^{2}=0.99$

Chaska: $y=-4.86 \mathrm{e}^{-5} \mathrm{x}^{3}+0.0026 \mathrm{x}^{2}+0.8 \mathrm{x}-14.4$ $R^{2}=0.96$

Yungay: $y=-4.38 \mathrm{e}^{-5} x^{3}+0.0012 x^{2}+0.91 x-14.8$ $R^{2}=0.96$ 


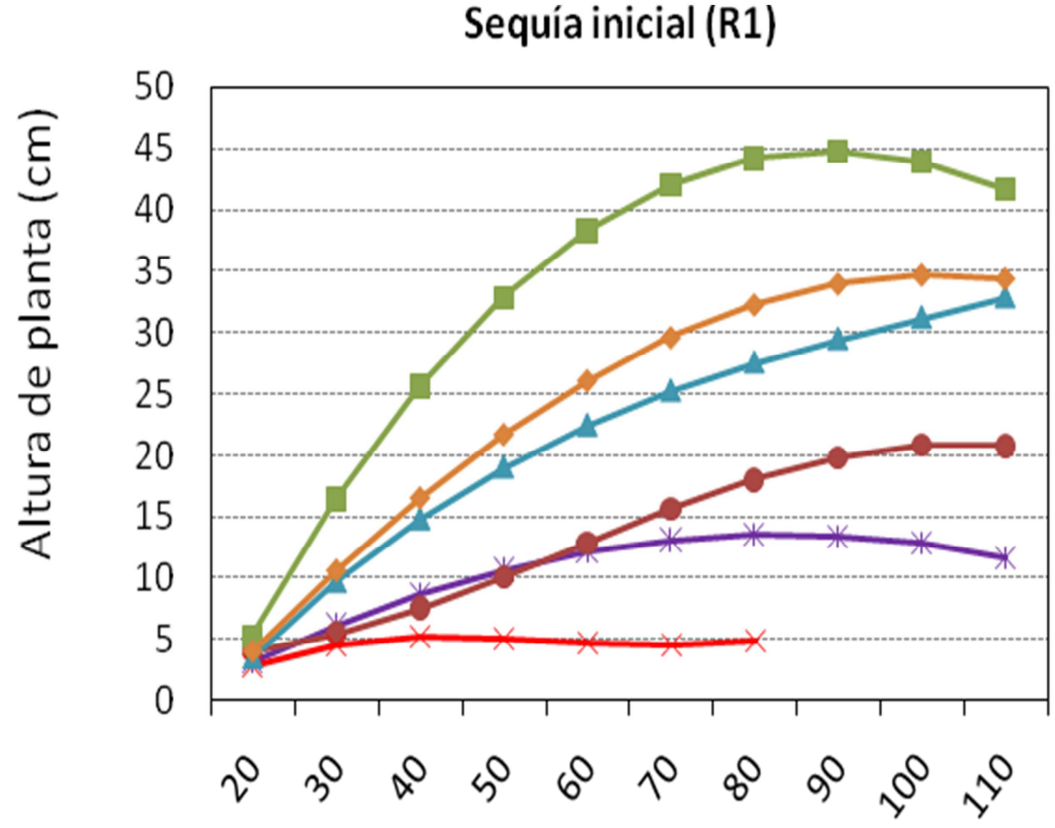

Días después de la siembra

$$
\begin{aligned}
& \text { * S. berthaultii } \\
& - \text { Jaspe } \\
& - \text { Waych'a } \\
& - \text { Desireé } \\
& - \text { Ch'aska } \\
& - \text { Yungay }
\end{aligned}
$$

S.berth: $y=-6.2 e^{-7} x^{3}-0.0025 x^{2}+0.43 x-4.43$

$$
R^{2}=0.95
$$

Jaspe: $y=-4.22 e^{-5} x^{3}+0.0073 x^{2}-0.142 x+4.24$ $R^{2}=0.97$

Waycha: $y=1.53 \mathrm{e}^{-5} \mathrm{x}^{3}-0.0113 \mathrm{x}^{2}+1.647 \mathrm{x}-23.17$ $R^{2}=0.91$

Desireé: $y=7.6 \mathrm{e}^{-5} \mathrm{x}^{3}-0.0128 \mathrm{x}^{2}+0.68 \mathrm{x}-6.21$ $R^{2}=0.89$

Chaska: $y=2.4 \mathrm{e}^{-5} \mathrm{x}^{3}-0.0075 \mathrm{x}^{2}+0.95 \mathrm{x}-12.7$ $R^{2}=0.98$

Yungay: $y=-8.3 e^{-6} x^{3}-0.0027 x^{2}+0.811 x-11.04$ $\mathrm{R}^{2}=0.99$ 
En el primer ensayo (Figura 5) se muestra que la sequía temprana R1 no afectó el número de entrenudos de Waych'a aun cuando este se inició en plena formación de sus entrenudos. Haciendo una relación al inicio de la sequía $R 1$ entre la altura de planta y el número de entrenudos de Waych'a, vemos que en este momento (55 dds) el primero (altura de planta) alcanza su máximo nivel y el segundo (número de entrenudos) continua en formación, aspecto que permite entender que la formación de entrenudos de Waych'a continua aun cuando la planta haya alcanzado su máxima altura.

Tanto en el primer ensayo (Figura 5b) como en el segundo (Figura $6 \mathrm{~b}$ ) el efecto de la sequía tardía R2 no fue perceptible estadísticamente para la mayoría de las variedades debido a que en este momento estas ya contaban con el total de sus entrenudos. En el primer ensayo (Figura 5b) solo Desirée fue afectada por esta sequía, lo que estaría mostrando que pese a su precocidad aún continúa formando entrenudos a un mes del inicio de su tuberización. Otro comportamiento que llama la atención es el de Luk'y que con esta sequía tardía incrementa su número de entrenudos de una manera significativa (Figura $6 b)$.

Número de hojas y número de ramas. En ambos ensayos (Figuras 7 y 8 ) en condiciones de un riego normal (R0), existen diferencias marcadas en el número de hojas por tallo principal. En el primer ensayo (Figura 6a) Jaspe, Waych'a, Ch'aska y Yungay alcanzaron el mayor número de hojas seguidos por $S$. berthaultii y finalmente Desirée como la de menor número de hojas. En la mayoría de las variedades entre los 70 y 80 dds cesa la formación de hojas y a partir de los 90 dds aproximadamente comienza la caída natural de las hojas viejas. En condiciones similares, Tourneux, et al (2003) también encontraron diferencias altamente significativas en el número de hojas del tallo principal y el número de tallos de diferentes especies y variedades de papa (Waych'a, Alpha, Clone CIP 382171.10, Ajahuiri, Luk'y y Janko Choquepito). 
Fig. 5. Variación del número de entrenudos por efecto de la sequía en seis variedades de papa. Resultados del primer ensayo, donde: $\mathbf{R} 0$ = Riego normal; $\mathbf{R} 1$ = Sequía inicio tuberización y $\mathbf{R 2}$ = Sequía a un mes del inicio de la tuberización.

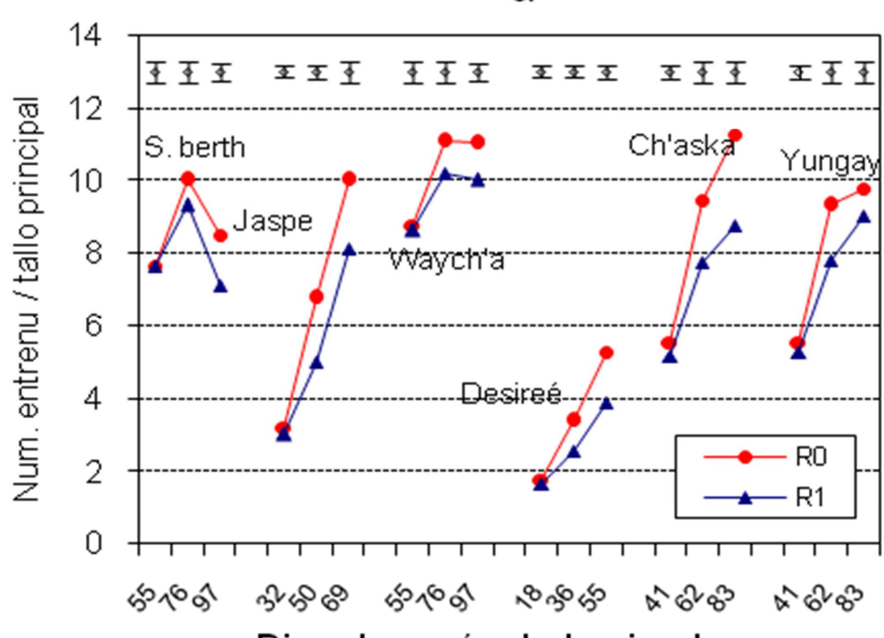

Dias después de la siembra b

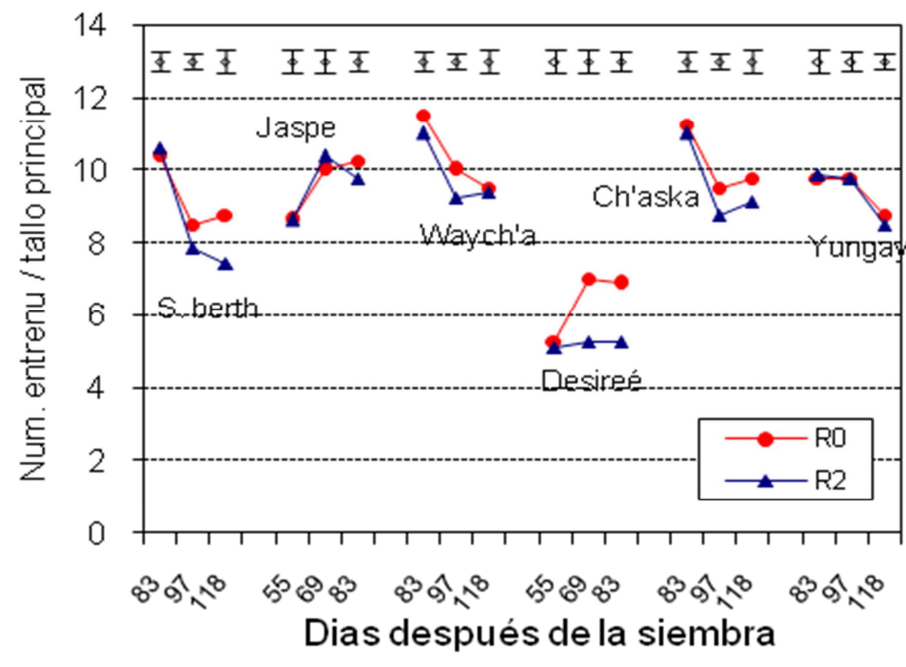


Fig. 6. Variación del número de entrenudos por efecto de la sequía en seis variedades de papa. Resultados del segundo ensayo, donde: $R 0$ = Riego normal; $R 1$ = Sequía temprana y R2 = Sequía tardía.

a

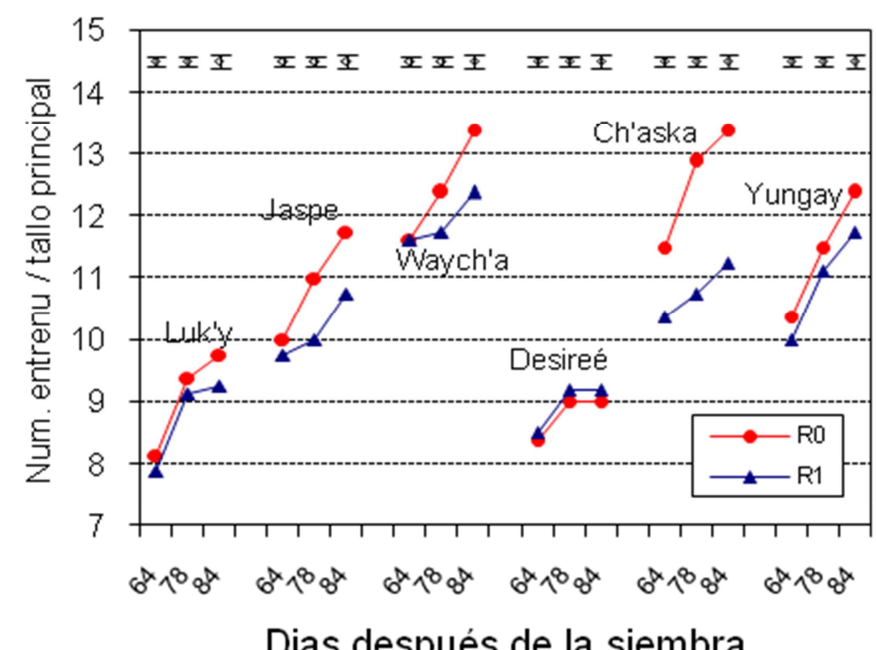

b

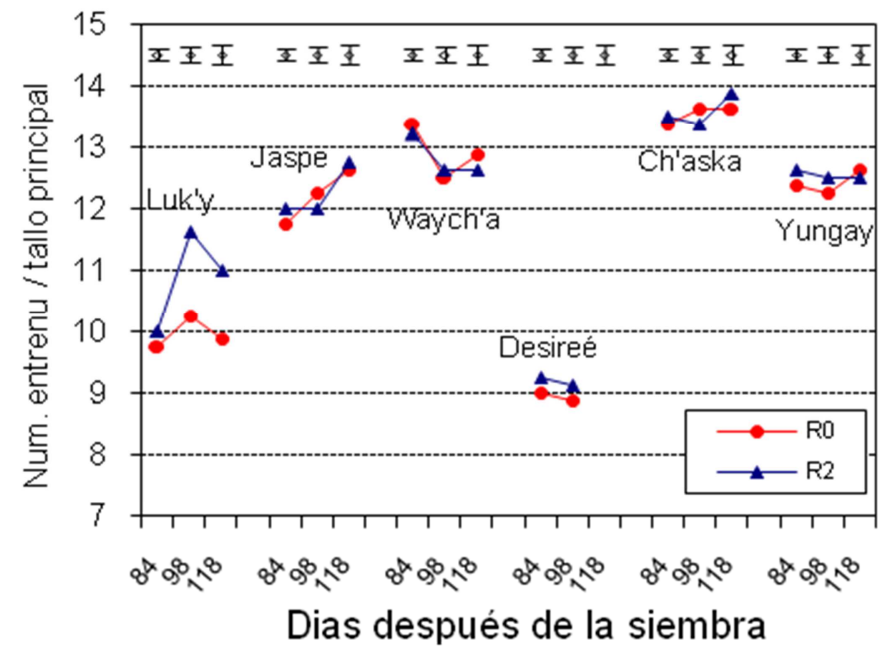


En el segundo ensayo (Figura 8a) la tendencia es similar pero se incluye Luk'y como una variedad con bajo número de hojas igual que Desirée. El comportamiento de Luk'y fue diferente al encontrado por Tourneux, et al (2003) quienes reportan un alto número de hojas para esta variedad asociado a un alto Índice de Área Foliar. Esta diferencia se debe a que ellos posiblemente cuantificaron el número total de hojas, incluyendo el de las ramas por tallo principal.

La sequía temprana R1 evitó la formación de hojas. En el primer ensayo (Figura 7a) este efecto para $S$. berthaultii, Jaspe, Waych'a, Desirée, Ch'aska y Yungay fue del 14, 15, 3, 12, 16 y $7 \%$ respectivamente y en el segundo ensayo (Figura $8 \mathrm{a}$ ) el efecto de esta sequía para Luk'y, Jaspe, Waych'a, Desirée, Ch'aska y Yungay fue del 16, 6.5, 3, 12, 9 y $4 \%$ respectivamente.

En ambos ensayos (Figuras 9a y 10b) en condiciones de un riego normal $(\mathrm{R} 0)$, existen diferencias marcadas en el número de ramas por tallo principal. En el primer ensayo (Figura 8a) Ch'aska alcanzó el mayor número de ramas seguida por Waych'a, Yungay, Jaspe y $S$. berthaultii y finalmente Desirée como la de menor número de ramas. En el segundo ensayo (Figura 10a) la tendencia es similar pero se incluye Luk'y como una variedad con bajo número de ramas al inicio pero que se va incrementado al final (Figura 10b). En la mayoría de las variedades continua la formación de ramas hasta aproximadamente los 100 dds.

La sequía temprana $\mathrm{R} 1$ evitó la formación de ramas por tallo principal. En el primer ensayo (Figura 9a) este efecto para $S$. berthaultii, Jaspe, Waych'a, Desirée, Ch'aska y Yungay fue del $29,28,0,0,25,0 \%$ respectivamente y en el segundo ensayo (Figura 10a) el efecto de esta sequía para Luk'y, Jaspe, Waych'a, Desirée, Ch'aska y Yungay fue del 4, 8.5, 0, 27, 18.5 y $6 \%$ respectivamente. En general el efecto de la sequía en el número de ramas tiene una tendencia similar al efecto en el número de hojas. 
Fig. 7. Variación del número de hojas por efecto de la sequía en seis variedades de papa. Resultados del primer ensayo, donde: $R 0$ = Riego normal; R1 = Sequía inicio tuberización y R2 = Sequía a un mes del inicio de la tuberización.

a

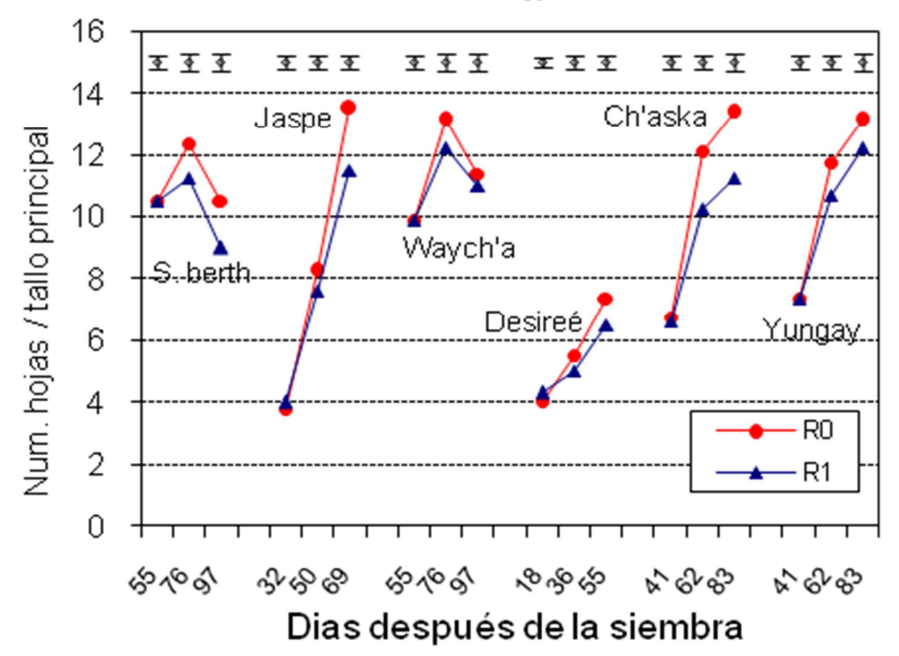

b

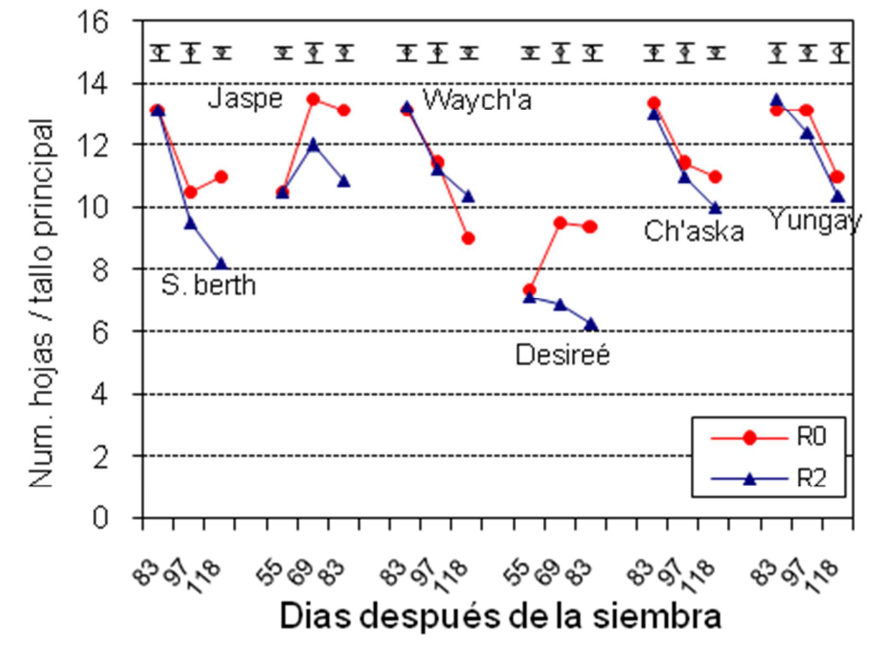


Fig. 8. Variación del número de hojas por efecto de la sequía en seis variedades de papa. Resultados del segundo ensayo, donde: $R 0$ = Riego normal; $R 1$ = Sequía temprana y R2 = Sequía tardía.

a

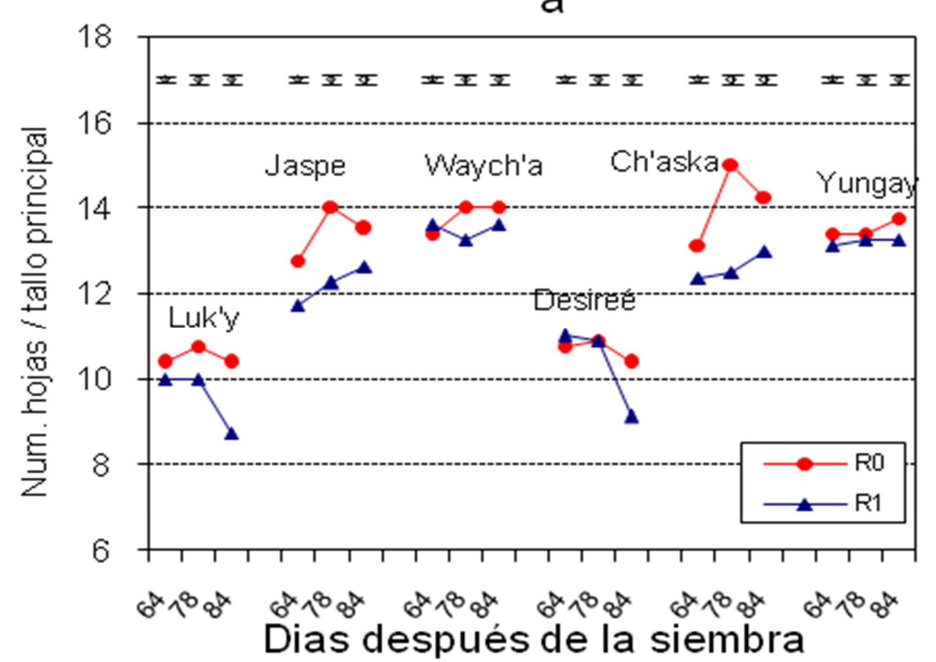

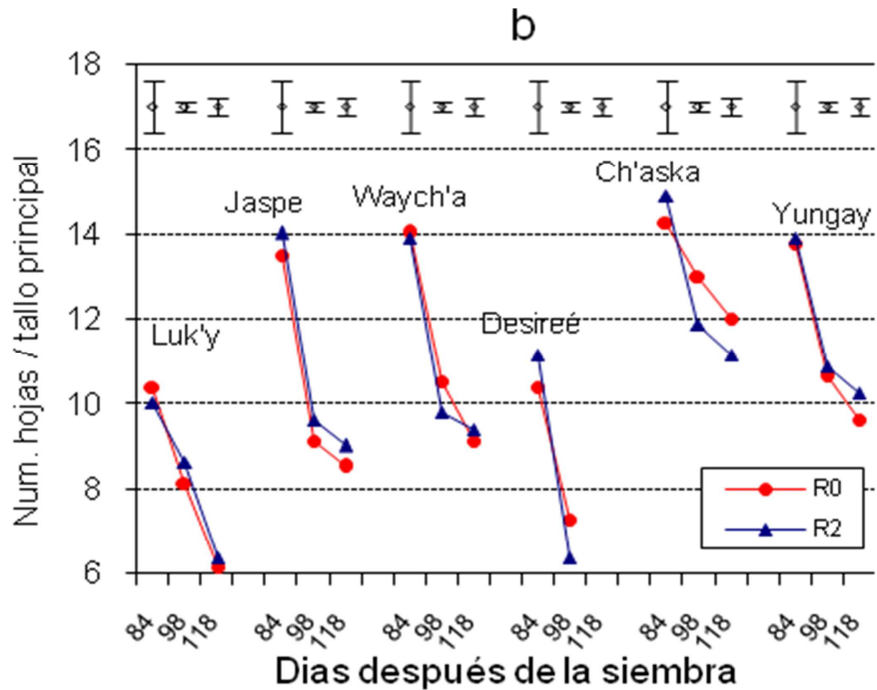


En ambos ensayos el efecto de la sequía tardía $\mathrm{R} 2$ en el número de hojas (Figuras $7 \mathrm{~b}$ y $8 \mathrm{~b}$ ) y en el número de ramas (figuras $9 \mathrm{~b}$ y 10b) no fue perceptible estadísticamente para la mayoría de las variedades, debido a que su inicio coincidió con la caída natural de sus hojas y ramas.

Si bien Tourneux, et al (2003) no encontraron diferencias significativas en el número de tallos de especies y variedades de papa por efecto de la sequía, no evaluaron el número de ramas por tallo.

Índice de daño de hojas y tallos. En la Figura 11 se muestra el índice de daño de hojas por efecto de la sequía temprana R1 evaluado solamente en el segundo ensayo. De acuerdo a la evolución de la susceptibilidad de las hojas a la sequía, se pueden destacar cinco grupos de comportamiento, siendo Desirée la variedad más afectada, seguida por Waych'a y Jaspe, ambas con un comportamiento similar, luego Yungay con un daño intermedio, a continuación Ch'aska y finalmente Luk'y con un daño que además de ser el menor, tiene una evolución diferente a las demás siendo imperceptible a un principio. A excepción de Desirée, las demás variedades luego de un riego, lograron recuperar sus hojas a su estado normal.

Si bien el número de hojas de Waych'a y Yungay fueron poco afectadas por la sequía temprana R1 (Figuras 7 y 8 ), el daño sintomático que presentan sus hojas muestra la susceptibilidad del follaje de estas variedades a la sequía. Contrariamente en Luk'y y Ch'aska que sufrieron la pérdida de sus hojas por efecto de la sequía (Figura 8) se podría pensar que esta reducción de sus hojas compensa el déficit hídrico de las hojas que quedan en la planta. Según Valladares (2004), la abscisión foliar durante el estrés es un mecanismo de evitación del estrés. Este comportamiento, especialmente de la variedad Luk'y expresa su capacidad de tolerancia a la sequía que le permite sobrevivir mejor. Por otra parte Desirée y Jaspe al disminuir el número de sus hojas por efecto de la sequía (Figuras $7 a$ y $8 a$ ) y sufrir el deterioro de sus hojas (Figura 11), muestra la gran fragilidad del follaje de estas variedades a la sequía. 
Fig. 9. Variación del número de ramas por efecto de la sequía en seis variedades de papa. Resultados del primer ensayo, donde: $\mathbf{R O}=$ Riego normal; $\mathbf{R} 1$ = Sequía inicio tuberización y R2 = Sequía a un mes del inicio de la tuberización.

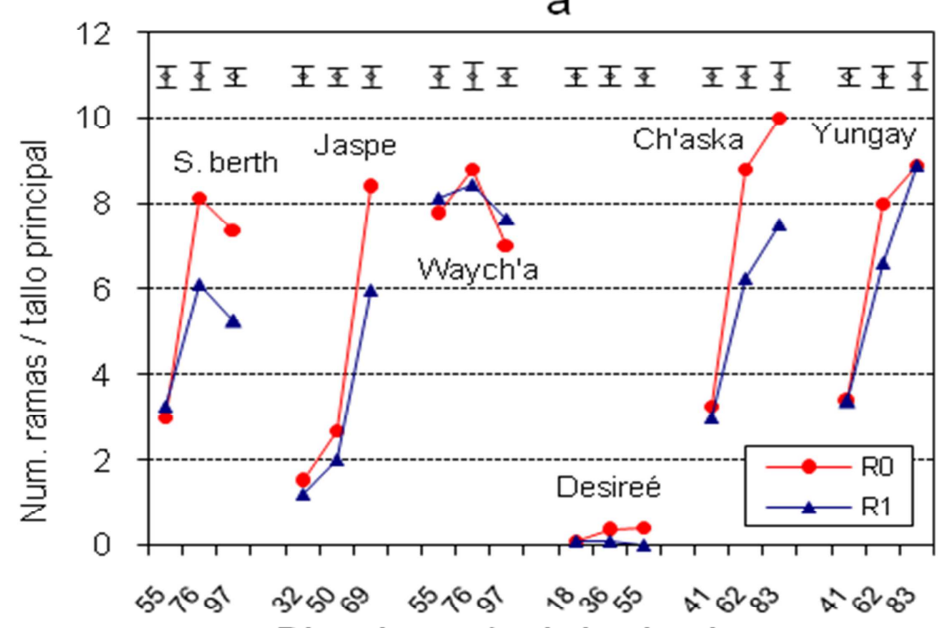

Dias después de la siembra b

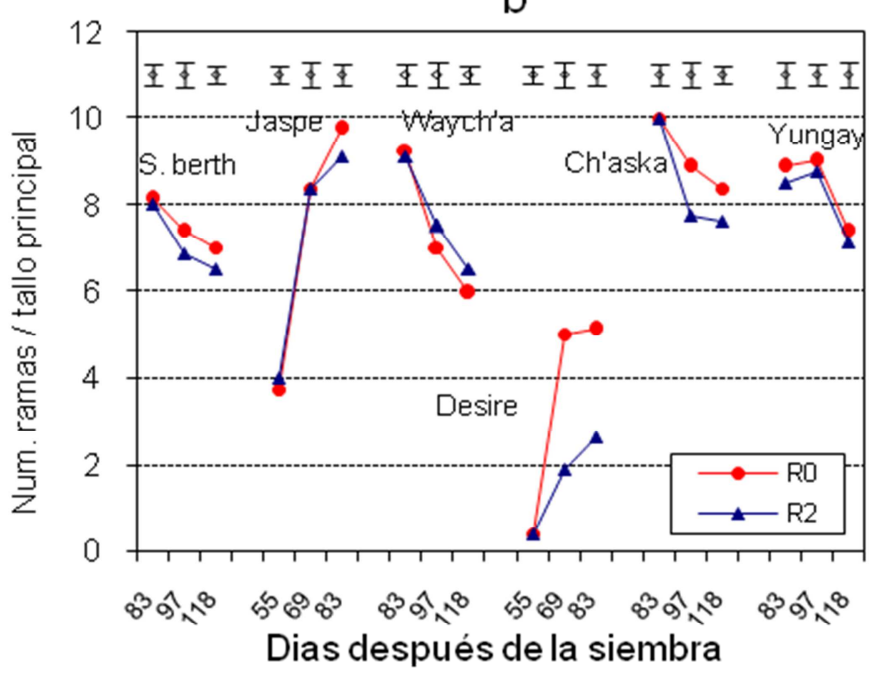


Fig. 10. Variación del número de ramas por efecto de la sequía en seis variedades de papa. Resultados del segundo ensayo, donde: $\mathbf{R 0}$ = Riego normal; $\mathbf{R 1}$ = Sequía temprana y $\mathbf{R 2}$ = Sequía tardía.
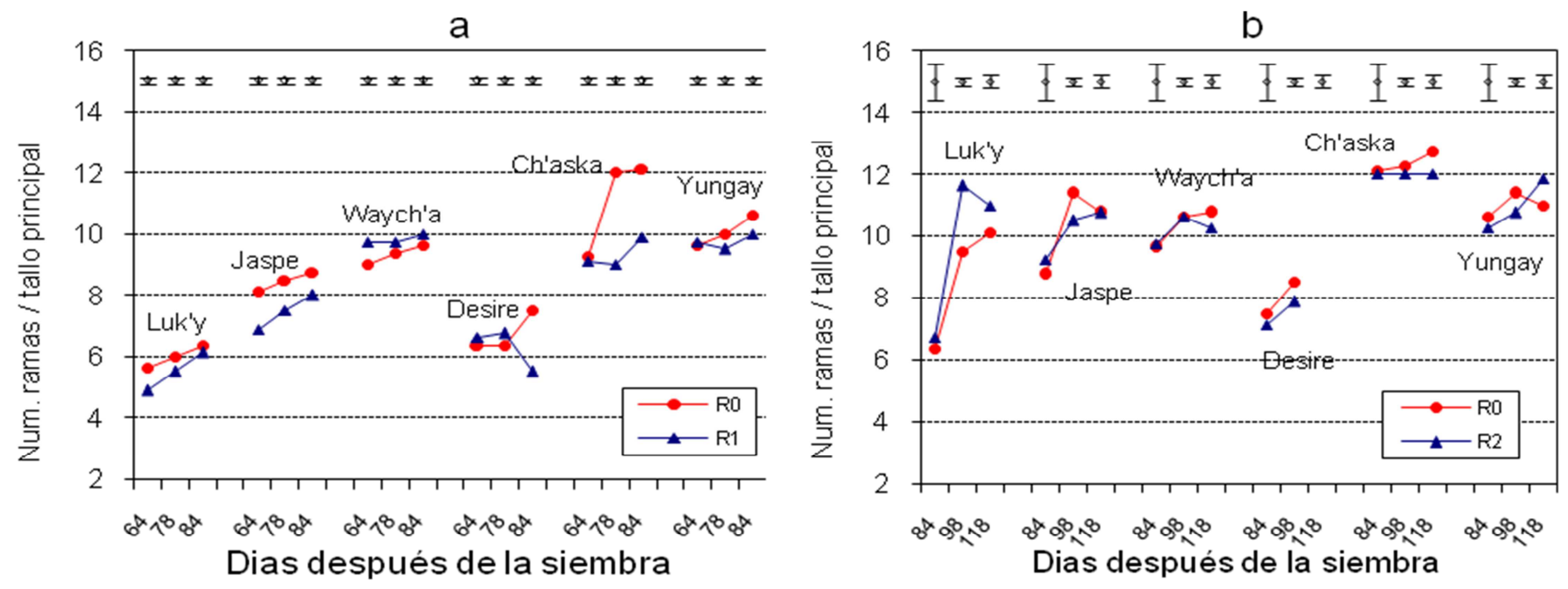
Fig. 11. Efecto de la sequía temprana (R1) en el daño de las hojas de seis variedades de papa. RO = Riego normal (sin sequía). Segundo ensayo.

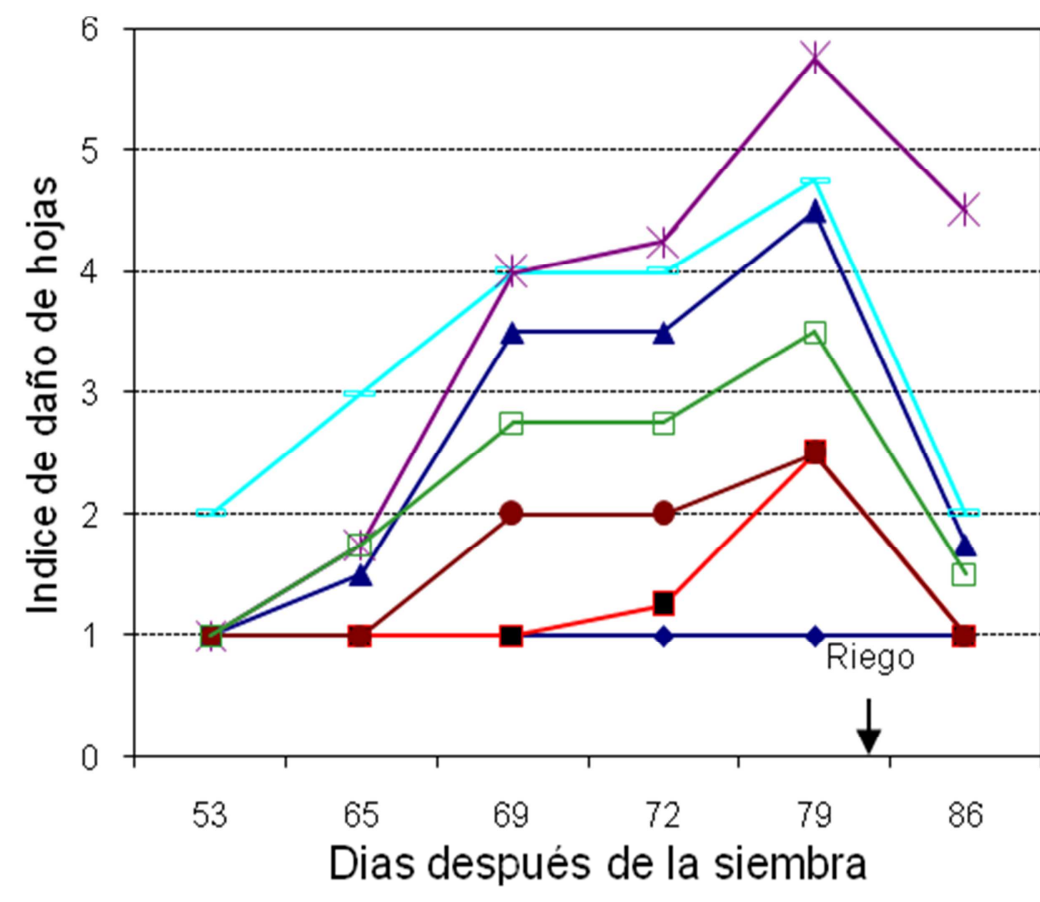

1 = hojas expandidas y turgentes 2 = hojas poco inclinadas $y$ turgentes $3=$ hojas poco inclinadas y poco turgentes

$4=$ hojas inclinadas y poco turgentes

5 = hojas inclinadas y flácidas

$6=$ hojas inclinadas, flácidas y arrugadas

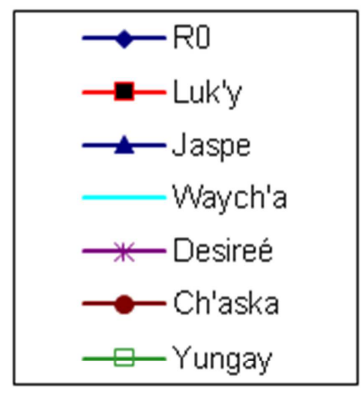

Dias después de la siembra 
Fig. 12 Efecto de la sequía temprana (R1) en el daño de los tallos de seis variedades de papa. RO = Riego normal (sin sequía). Segundo ensayo.

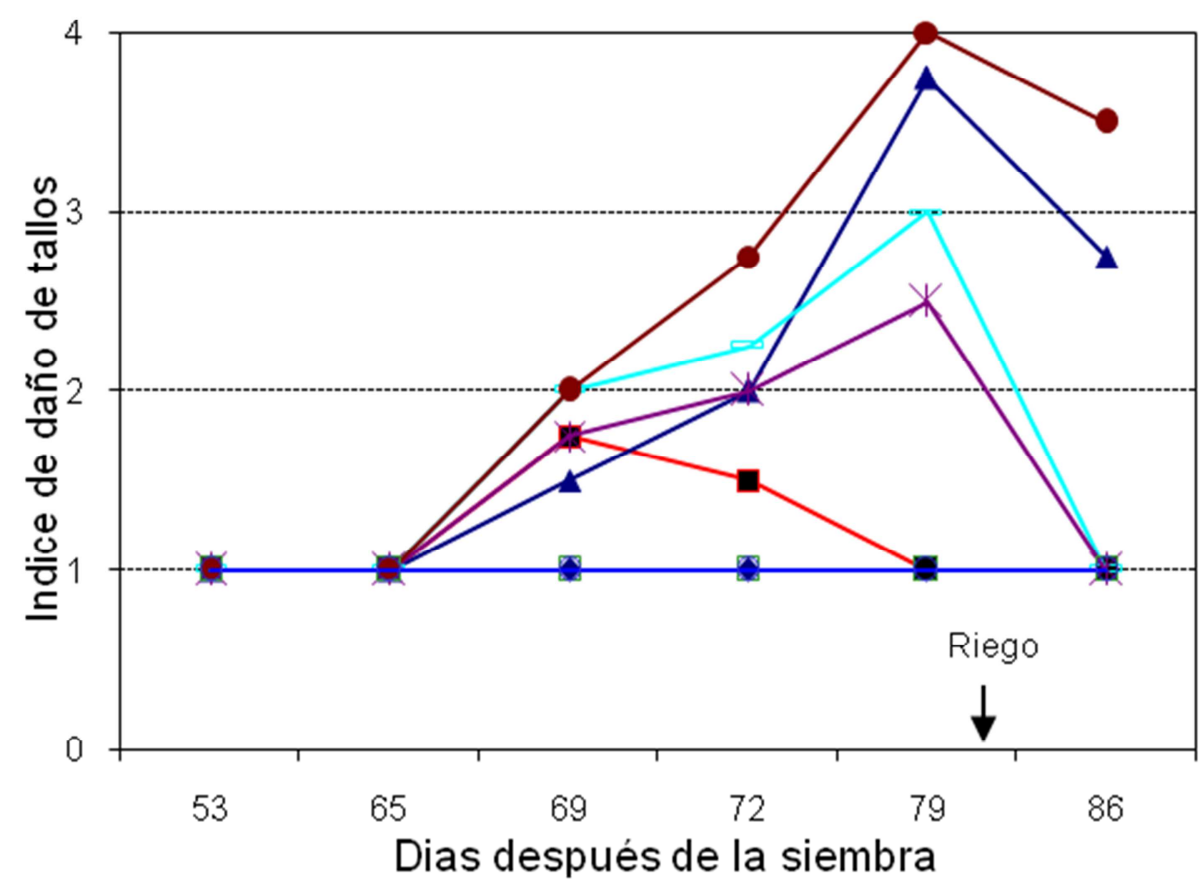

$1=$ tallos erectos y turgentes

$2=$ tallos erectos y poco turgentes

3 = tallos inclinados y poco flácidos

4 = tallos postrados y flácidos

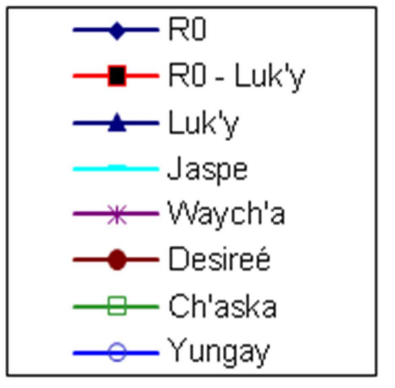

Dias después de la siembra 
En la Figura 12 se muestra el índice de daño de tallos evaluado en el segundo ensayo, por efecto de la sequía temprana R1. Para algunas variedades, el daño de la sequía en los tallos no esta relacionado al daño en sus hojas, como es el caso de Yungay y Chask'a cuyos tallos no fueron afectados visiblemente por la sequía. Por otra parte, si bien Luk'y expresa su tolerancia a la sequía en sus hojas no ocurre lo mismo en sus tallos. La aparente baja capacidad de recuperación de sus tallos luego de un riego de recuperación está ligada a la tendencia natural de esta variedad de postrar sus tallos en el suelo aún en condiciones de buena humedad en el suelo.

En las demás variedades, el daño en sus tallos tienen la misma tendencia al daño en sus hojas, siendo Desirée la más sensible. Luego del riego de recuperación, solo Jaspe y Waych'a lograron recuperar sus tallos a su estado normal y no así Desirée.

Siendo que Waych'a y Jaspe (en orden de importancia) fueron las más afectadas en sus hojas y tallos, se debe resaltar la gran capacidad de recuperación de la turgencia de sus hojas y tallos luego de un riego de recuperación, aspecto que muestra la parcial tolerancia que tienen estas variedades a la sequía. Según Valladares (2004), la capacidad de rebrotar de las plantas después de un periodo de estrés es considerado como un mecanismo de tolerancia a la sequía y a otros factores abióticos.

Índice de raíz (IR). El índice de raíz (IR) es la relación entre la biomasa radicular y la biomasa foliar. Un alto IR muestra que la variedad tiene una mayor masa radicular por unidad de masa de follaje producido. Esta variable que fue evaluada en el segundo ensayo (Figura 13), muestra que en condiciones de un riego normal (R0) existe diferencias entre variedades destacando Ch'aska y Desirée como las de mayor IR seguidas de Jaspe y Yungay con un IR intermedio y luego Waych'a y finalmente Luk'y como la de más bajo IR en condiciones de riego normal. Ch'aska y Desirée son dos variedades totalmente contrastantes en cuanto a su desarrollo vegetativo. Si bien Ch'aska tiene una gran masa vegetativa en relación a Desirée, 
el alto IR de ambas variedades muestra que sus biomasas radiculares son proporcionales a sus masas foliares.

En Waych'a la sequía temprana R1 incrementó el índice de raíz, lo que puede representar dos hipótesis: a) que esta sequía le indujo a una mayor acumulación de materia seca en sus raíces sin afectar marcadamente su masa foliar 0 contrariamente b) que redujo su biomasa foliar sin afectar su masa radicular. Los resultados del follaje (Figuras 7a y 8 a para hojas y 9a y 10a para ramas) muestran que Waych'a al no ser afectada en su número de hojas y ramas se estaría ajustando mas a la primera hipótesis aspecto que estaría mostrando la evasión a la sequía de esta variedad debido a que la producción de mayor cantidad de raíces le estaría permitiendo explorar con mayor eficiencia el agua del suelo y así evitar un mayor efecto de la sequía. En el resto de las variedades si bien hubo efecto de la sequía, este no fue estadísticamente significativo. De la misma manera, el efecto de la sequía tardía (R2) no fue significativo en la mayoría de las variedades, salvo en la variedad Jaspe.

En condiciones similares, Tourneux, et al (2003) no encontraron diferencias significativas por efecto de la sequía en la materia seca de raíces de diferentes especies y variedades de papa (Waych'a, Alpha, Clone CIP 382171.10, Ajahuiri, Luk'y y Janko Choquepito). Estos mismos investigadores encontraron que la relación materia seca raíz/follaje de Luk'y es alta en relación a las otras variedades aspecto contrario al encontrado en el presente estudio. En relación al efecto de la sequía, estos investigadores encontraron que Waych'a es la variedad que aumenta significativamente su relación materia seca raíz/follaje y no así las otras variedades, aspecto coincidente con el presente estudio. La disponibilidad de agua afecta la relación entre el crecimiento de la parte aérea y la raíz; la raíz continúa su desarrollo mientras que la parte aérea deja de crecer por causa del estrés. Así, las plantas son capaces de continuar el desarrollo de sus raíces en búsqueda de agua en zonas más profundas del suelo (Potters et al., 2007; Shao et al., 2008). 
Fig. 13. Efecto de la sequía en el Índice de Raíz (IR) de seis variedades de papa. Segundo ensayo. $\mathbf{R 0}$ = Riego normal; $R 1$ = Sequía temprana y $\mathbf{R} 2$ = Sequía tardía. La barra (s.e.) solo permite la comparación estadística entre tratamientos dentro de cada variedad.

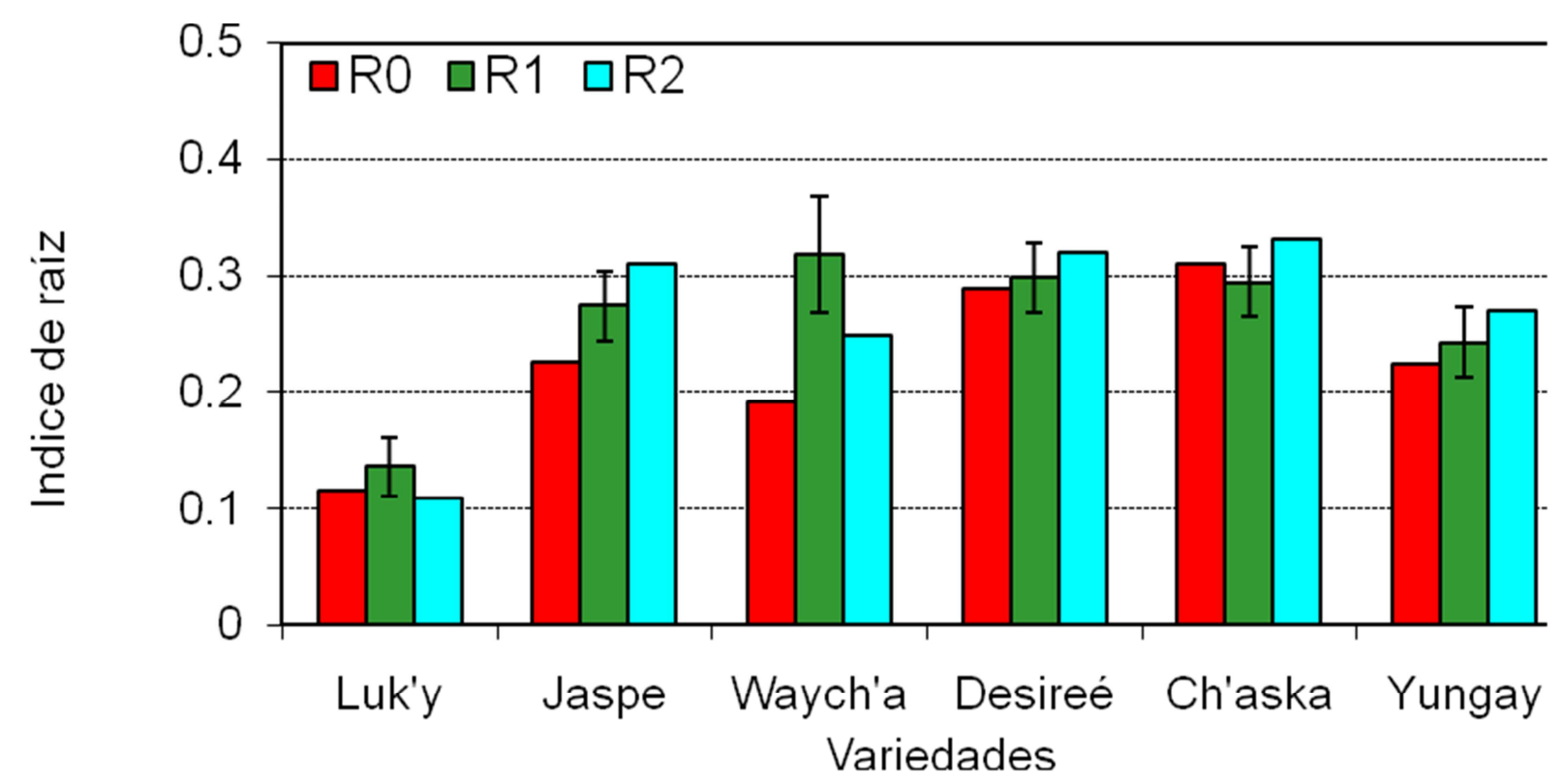


Fig. 14. Efecto de la sequía en el Índice de Cosecha (IC) de seis variedades de papa. Segundo ensayo. $R 0$ = Riego normal; R1 = Sequía temprana y R2 = Sequía tardía. La barra (s.e.) solo permite la comparación estadística entre tratamientos dentro de cada variedad.

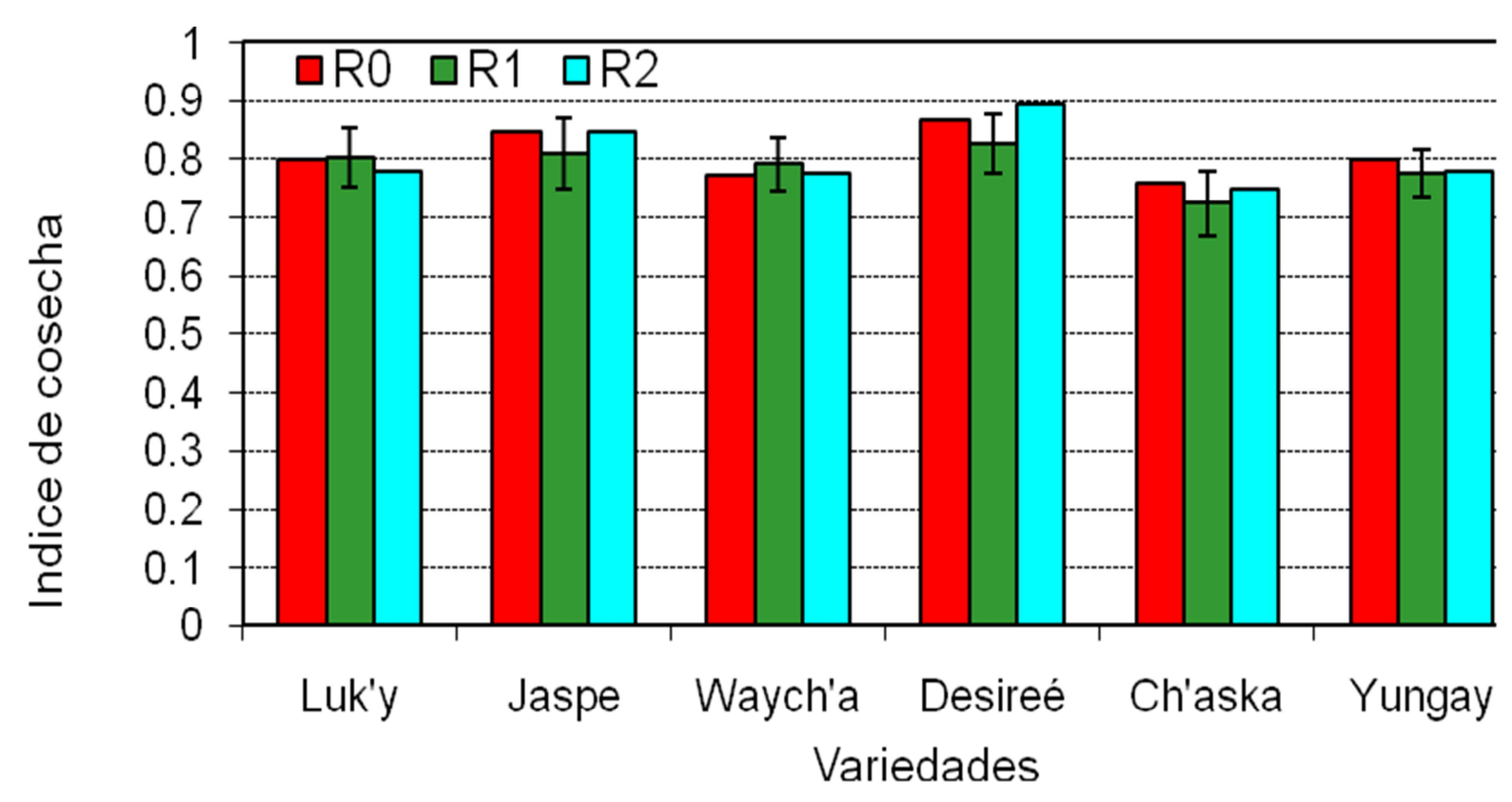


Índice de cosecha (IC). En la Figura 14 se muestra el efecto de la sequía en el índice de cosecha de seis variedades de papa (Biomasa tubérculos / biomasa total). En condiciones de un riego normal (R0), existen diferencias en el índice de cosecha entre las variedades. Desirée tiene el mayor índice (0.88) seguida de Jaspe (0.86) y Yungay (0.8) con un índice intermedio y a continuación Luk'y (0.81), Waych'a (0.78) y Ch'aska (0.77) como las de menor índice de cosecha. Si bien Ch'aska tiene una gran masa foliar en relación a Desirée, en ambos casos la biomasa de sus tubérculos es proporcional a sus masas foliares. Tourneux, et al (2003) también observaron diferencias altamente significativas entre genotipos de papa para el IC. Las variedades de maduración temprana como Alpha, tenían un alto IC, mientras que la variedades de maduración tardía como Luk'y tenía un bajo IC (valores de 0.8 y 0.5 respectivamente), aspecto muy coincidente con el presente estudio. Jefferies (1992) también observó que las variedades de papa de maduración temprana (precoces) muestran valores altos de IC.

Estadísticamente la sequía no afectó el índice de cosecha de las variedades estudiadas, lo que significa que el efecto en la biomasa de los tubérculos de todas las variedades fue proporcional al efecto en la biomasa de sus follajes. Contrariamente, Tourneux, et al (2003) encontraron que la variedad Luk'y disminuye su IC por efecto de la sequía.

\section{Componentes de rendimiento}

\section{a. Número de tubérculos}

En los cuadros 3 y 4 se presentan el efecto de la sequía en el porcentaje del número de tubérculos al momento de la cosecha, en el primer y segundo ensayo respectivamente. 
Cuadro 3. Efecto de la sequía (R1 y R2) en el porcentaje de tubérculos según su tamaño. Primer ensayo.

\begin{tabular}{|c|c|c|c|c|c|c|c|c|c|c|}
\hline & \multicolumn{5}{|c|}{$(\mathrm{R} 1 / \mathrm{R} 0) \times 100$} & \multicolumn{5}{|c|}{$(\mathrm{R2} / \mathrm{R} 0) \times 100$} \\
\hline Variedad & $1^{a}$ & $2^{a}$ & $3^{a}$ & $4^{a}$ & $5^{a}$ & $1^{a}$ & $2^{a}$ & $3^{a}$ & $4^{\mathrm{a}}$ & $5^{\mathrm{a}}$ \\
\hline $\begin{array}{l}\text { S. } \\
\text { berthaultii } \\
\text { Jaspe }\end{array}$ & 0 & 0 & 54 & 68 & $\begin{array}{l}88 \\
12\end{array}$ & 0 & 0 & 88 & 91 & $\begin{array}{l}88 \\
10\end{array}$ \\
\hline & 0 & 0 & 38 & 90 & $\begin{array}{c}0 \\
10\end{array}$ & 0 & $\begin{array}{c}0 \\
11\end{array}$ & $\begin{array}{l}55 \\
11\end{array}$ & 85 & 6 \\
\hline Desirée & 0 & 0 & 57 & $\begin{array}{l}97 \\
12\end{array}$ & $\begin{array}{c}9 \\
10\end{array}$ & 0 & 3 & 8 & 85 & 80 \\
\hline Ch'aska & 0 & 44 & 87 & $\begin{array}{c}9 \\
12\end{array}$ & $\begin{array}{c}0 \\
16\end{array}$ & 0 & 74 & 87 & $\begin{array}{l}82 \\
10\end{array}$ & $\begin{array}{l}95 \\
10\end{array}$ \\
\hline Yungay & 0 & 0 & 29 & $\begin{array}{c}5 \\
13 \\
2\end{array}$ & $\begin{array}{c}1 \\
12 \\
1\end{array}$ & 0 & 20 & 66 & 9 & $\begin{array}{c}2 \\
13 \\
2\end{array}$ \\
\hline
\end{tabular}

Tamaño de tubérculos $\left(1^{\mathrm{a}}:>5.5 \mathrm{~cm}, 2^{\mathrm{a}}: 5.5-4.5 \mathrm{~cm}, 3^{\mathrm{a}}: 4.5-3.5 \mathrm{~cm}, 4^{\mathrm{a}}: 3.5-2.5 \mathrm{~cm}\right.$ y $\left.5^{\mathrm{a}}:<2.5 \mathrm{~cm}\right)$ $\mathrm{R} 0$ = Riego normal a capacidad de campo

$\mathrm{R} 1$ = Sequía al inicio de la tuberización de cada variedad (Sequía temprana)

$\mathrm{R} 2$ = Sequía a un mes del inicio de la tuberización de cada variedad (Sequía tardía). 
Cuadro 4. Efecto de la sequía (R1 y R2) en el porcentaje de tubérculos según su tamaño. Segundo ensayo.

\begin{tabular}{|c|c|c|c|c|c|c|c|c|}
\hline \multirow[b]{2}{*}{ Variedad } & \multicolumn{4}{|c|}{$(R 1 / R 0) \times 100$} & \multicolumn{4}{|c|}{$(R 2 / R 0) \times 100$} \\
\hline & $1^{\underline{a}}$ & $2^{\mathrm{a}}$ & $3^{\underline{a}}$ & $4^{\mathrm{a}}$ & $1^{\mathrm{a}}$ & $2^{\mathrm{a}}$ & $3^{a}$ & $4^{\mathrm{a}}$ \\
\hline Luk'y & 0 & 64 & 55 & 134 & 0 & 97 & 74 & 86 \\
\hline Jaspe & 53 & 87 & 102 & 107 & 92 & 103 & 92 & 107 \\
\hline Waych'a & 60 & 100 & 75 & 129 & 60 & 127 & 73 & 100 \\
\hline Desirée & 0 & 29 & 82 & 197 & 100 & 69 & 97 & 109 \\
\hline Ch'aska & 0 & 41 & 92 & 107 & 64 & 73 & 89 & 100 \\
\hline Yungay & 0 & 52 & 118 & 215 & 105 & 68 & 86 & 119 \\
\hline
\end{tabular}

Tamaño de tubérculos $\left(1^{\mathrm{a}}:>5.5 \mathrm{~cm}, 2^{\underline{a}}: 5.5-4.5 \mathrm{~cm}, 3^{\underline{a}}: 4.5-3.5 \mathrm{~cm}\right.$ y $\left.4^{\underline{a}}:<3.5 \mathrm{~cm}\right)$

$\mathrm{R} 0$ = Riego normal a capacidad de campo

R1 = Sequía al inicio de la tuberización de la variedad Waych'a (Sequía temprana)

R2 = Sequía a un mes del inicio de la tuberización de Waych'a (Sequía tardía). 
Fig. 15. Efecto de la sequía en el rendimiento total y rendimiento relativo de seis variedades de papa evaluados en dos años consecutivos, donde: $\mathbf{R O}=$ Riego normal; $\mathbf{R} \mathbf{1}=$ Sequía temprana y R2 = Sequía tardía. La barra (s.e.) solo permite la comparación estadística entre tratamientos dentro de cada variedad.
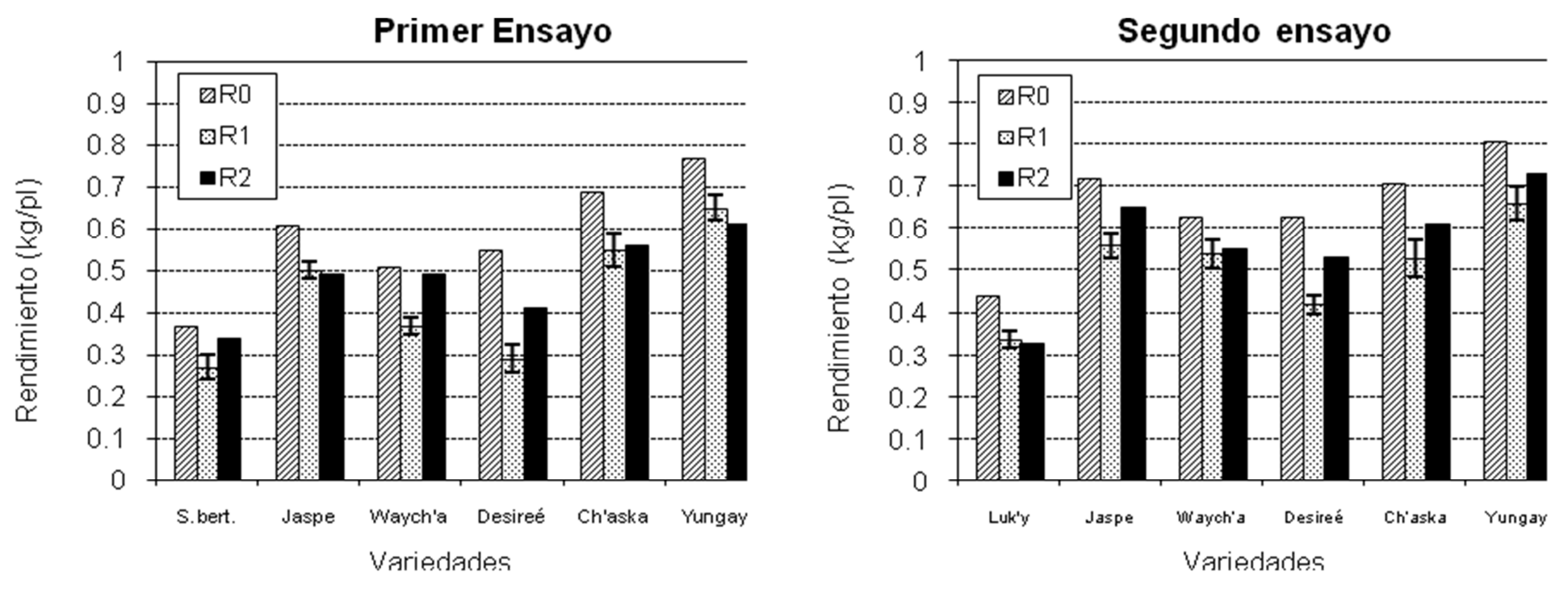

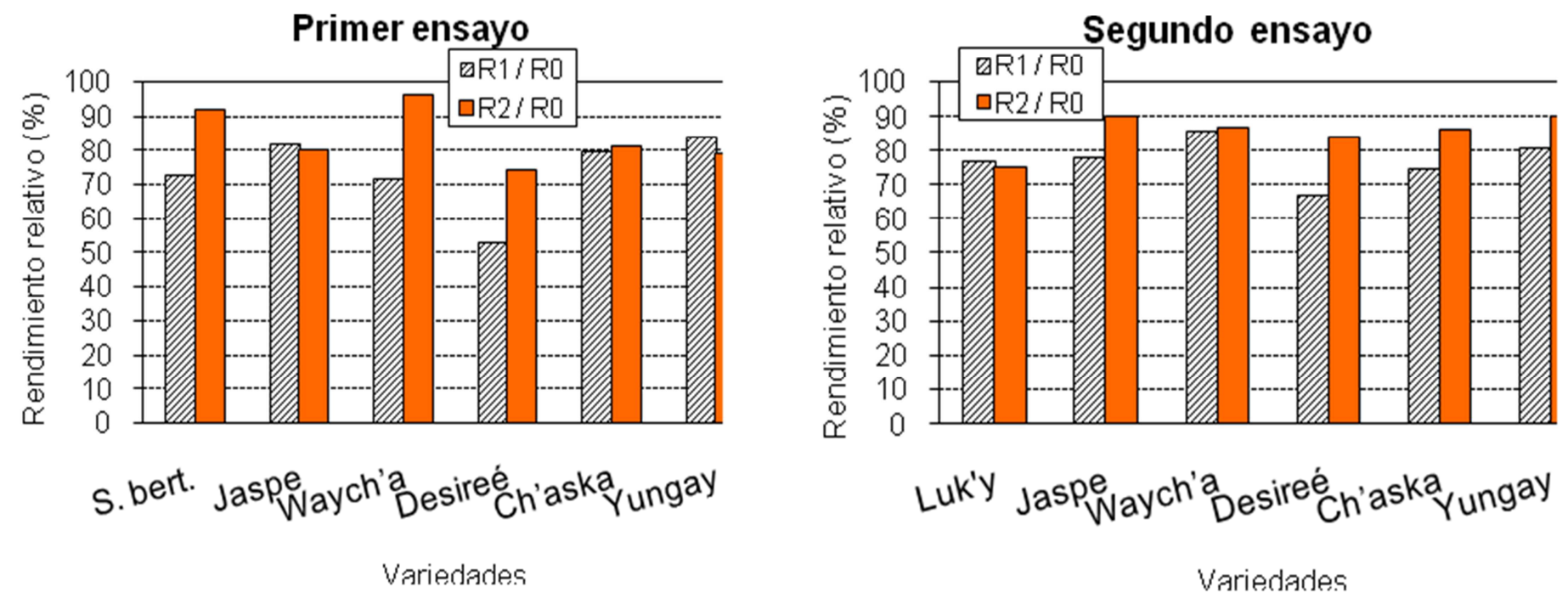
En ambos ensayos la sequía temprana $\mathrm{R} 1$ indujo a formar tubérculos de menor tamaño $\left(4^{\mathrm{a}}\right.$ y $\left.5^{\mathrm{a}}\right)$ a todas las variedades excepto a $S$. berthaultii (primer ensayo). Según Martinez y Moreno (1992), la formación de tubérculos pequeños por efecto de un estrés abiótico constituye un mecanismo de respuesta natural a la sobrevivencia de este cultivo. La sequía temprana $\mathrm{R} 1$ también afectó la formación de tubérculos de tamaño $2^{\mathrm{a}}$ y $3^{\mathrm{a}}$ en relación a la sequía tardía $\mathrm{R} 2$. En general el efecto de la sequía tardía (R2) fue menos marcada al de la sequía temprana (R1), salvo en Yungay que por ser una variedad de ciclo largo esta sequía aun indujo la formación de tubérculos pequeños. En algunos casos como en Waych'a esta sequía tardía R2 indujo a una mayor formación de tubérculos de tamaño $\left(2^{a}\right.$ y $\left.3^{a}\right)$, aspecto que estaría mostrando que esta variedad minimiza el efecto de una sequía tardía llenado más aceleradamente sus tubérculos pequeños.

Tourneux, et al (2003) observaron que el número de tubérculos por planta de las variedades precoces no fue afectada por la sequía, pero si de las variedades tardías como Luk'y. Mackerron y Jefferies (1996) demostraron que la sequía reduce el número de tubérculos cuando esta ocurre durante el inicio de la tuberización. Esto podría explicar por qué no se observó cambio en el número de tubérculos de la variedad Desirée.

\section{b. Rendimiento de tubérculos}

Como se ve en la Figura 15, en ambos ensayos en condiciones de riego normal (R0) existe, diferencias marcadas en el rendimiento entre variedades, destacando las variedades Yungay y Ch'aska seguidos de Jaspe, Desirée y Waych'a y finalmente $S$. berthaultii y Luk'y.

El análisis del rendimiento relativo de la Figura 15 muestra diferencias entre la sequía temprana $\mathrm{R} 1$ y la sequía tardía R2 según sea la variedad. En el primer ensayo Desirée, $S$. berthaultii y Waych'a son las más afectadas por la sequía temprana R1 que por la sequía tardía R2. En Jaspe, Ch'aska y Yungay el efecto de ambas sequías es similar. En $S$. berthaultii y Waych'a no se observa un efecto marcado de la sequía tardía 
R2. En el segundo ensayo las tendencias son similares, con la diferencia de que en Waych'a los efectos de ambas sequías son similares y menos marcadas que en el primer ensayo y en Jaspe, Ch'aska y Yungay el efecto de la sequía tardía R2 es de menor grado que en el primer ensayo. En la variedad Luk'y, ambas sequías tuvieron el mismo efecto.

De acuerdo a las pérdidas de rendimiento por efecto de la sequía y a una escala de daño arbitraria (Tolerante: 0-10\%, Poco tolerante: $11-20 \%$, Medio sensible: $21-30 \%$ y Sensible: $>$ $31 \%$ ), las variedades estudiadas se pueden agrupar de la siguiente manera:

\begin{tabular}{|l|c|c|}
\hline Variedad & Sequía temprana & Sequía tardía \\
\hline Desirée & Sensible & Medio sensible - poco tolerante \\
Jaspe & Medio sensible - poco tolerante & Poco tolerante - tolerante \\
Waych'a & Medio sensible - poco tolerante & Poco tolerante - tolerante \\
Ch'aska & Medio sensible - poco tolerante & Poco tolerante \\
Yungay & Poco tolerante & Poco tolerante - tolerante \\
S. berthaultii & Medio sensible & Tolerante \\
Luk'y & Medio sensible & Medio sensible \\
\hline
\end{tabular}

Susceptibilidad del rendimiento y su correlación con la susceptibilidad de las variables morfológicas al daño por sequía. En los cuadros 5 y 6 del primer y segundo ensayo respectivamente, se presenta el grado de susceptibilidad al daño por sequía del rendimiento y de las variables morfológicas y su correlación. Este grado de susceptibilidad se calculó en base a: 1 - R1/R0. Cuando mayor sea el coeficiente mayor será la susceptibilidad al daño y viceversa.

Se espera que esta correlación permita identificar variables morfológicas fácilmente medibles y asociadas con la productividad del cultivo y que puedan usarse como indicadores para la elección de material progenitor con tolerancia a la sequía que pueda usarse en programas de mejoramiento. 
Cuadro 5. Correlación ( $r$ entre el grado de susceptibilidad al daño por sequía del rendimiento y de variables morfológicas, de seis variedades de papa. Primer ensayo.

\begin{tabular}{|c|c|c|c|c|c|c|c|c|c|}
\hline & \multicolumn{9}{|c|}{1 - R1 / R0 } \\
\hline Variedad & Rend. & $\begin{array}{c}\text { Altura de } \\
\text { planta }\end{array}$ & $\begin{array}{l}\text { Número de } \\
\text { entrenudos }\end{array}$ & $\begin{array}{l}\text { Número } \\
\text { de hojas }\end{array}$ & $\begin{array}{l}\text { Número de } \\
\text { ramas }\end{array}$ & $\begin{array}{c}\text { Long. del } \\
\text { Penúltimo } \\
\text { Entrenudo (PE) }\end{array}$ & $\begin{array}{l}\text { Longitud de } \\
\text { hoja del PE }\end{array}$ & $\begin{array}{c}\text { Longitud } \\
\text { de raquis } \\
\text { de la hoja } \\
\text { del PE }\end{array}$ & $\begin{array}{l}\text { Longitud de } \\
\text { peciolo de la } \\
\text { hoja del PE }\end{array}$ \\
\hline S. berth. & 0.27 & 0.38 & 0.16 & 0.14 & 0.29 & 0.24 & 0.28 & 0.36 & 0.43 \\
\hline Jaspe & 0.18 & 0.49 & 0.19 & 0.15 & 0.28 & 0.38 & -0.54 & -0.94 & -0.56 \\
\hline Waych'a & 0.27 & 0.05 & 0.09 & 0.03 & -0.09 & -0.02 & 0.03 & -0.15 & -0.68 \\
\hline Desirée & 0.47 & 0.52 & 0.26 & 0.12 & 1.00 & 0.52 & & & \\
\hline Ch'aska & 0.20 & 0.39 & 0.22 & 0.16 & 0.25 & 0.12 & -0.89 & -1.17 & -1.44 \\
\hline Yungay & 0.15 & 0.24 & 0.08 & 0.07 & 0.00 & 0.20 & 0.04 & 0.08 & 0.10 \\
\hline \multirow{2}{*}{\multicolumn{10}{|c|}{$\frac{r=0.30}{r=0.58}$}} \\
\hline & & & & & & & & & \\
\hline \multicolumn{10}{|c|}{$r=0.30$} \\
\hline \multicolumn{10}{|c|}{$r=0.82$} \\
\hline \multirow{2}{*}{\multicolumn{10}{|c|}{$\begin{array}{r}r=0.52 \\
r=0.41\end{array}$}} \\
\hline & & & & & & & & & \\
\hline \multirow{2}{*}{\multicolumn{10}{|c|}{$\frac{r=0.35}{r=0.08}$}} \\
\hline & & & & & & & & & $r=0.08$ \\
\hline
\end{tabular}


Cuadro 6. Correlación ( $r$ ) entre el grado de susceptibilidad al daño por sequía del rendimiento y de variables morfológicas, de seis variedades de papa. Segundo ensayo.

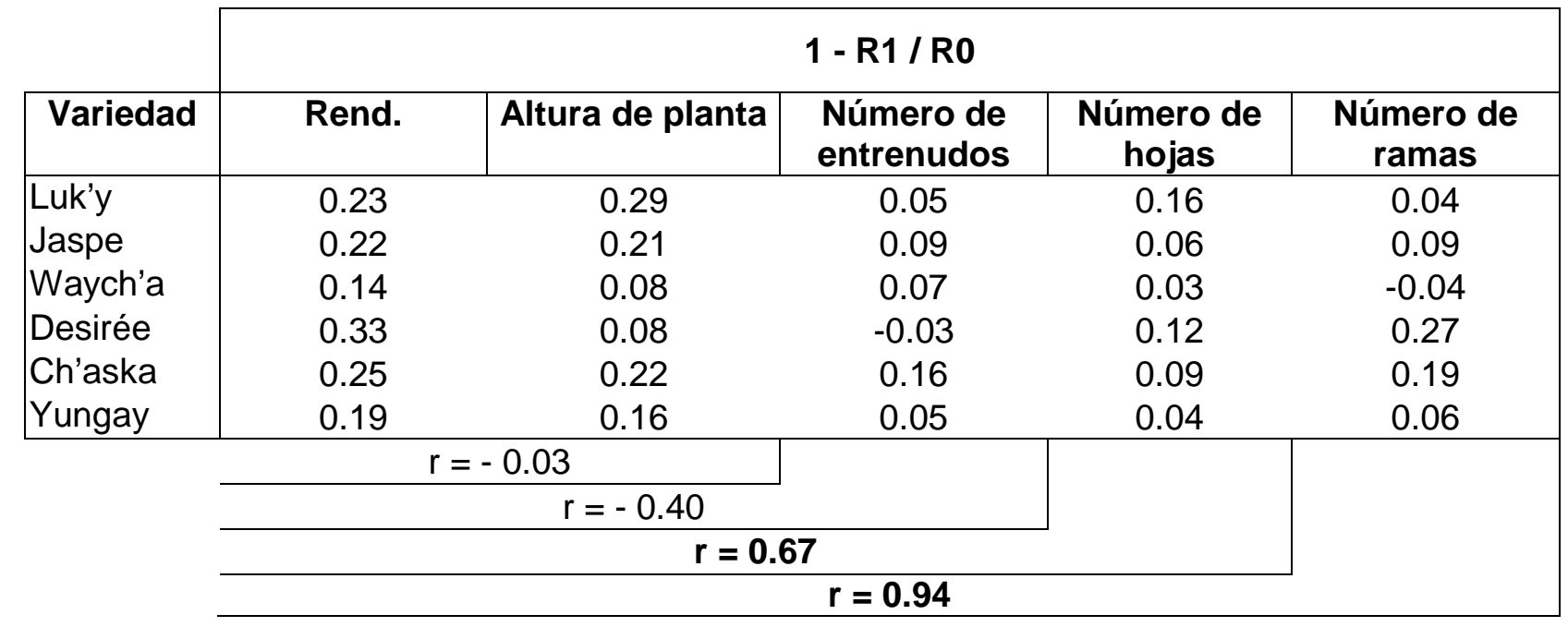

Nivel de significación $5 \%$

R0 = Riego normal a capacidad de campo (testigo)

R1 = Sequía al inicio de la tuberización de la variedad Waych'a (Variedad testigo).

Los datos de los parámetros morfológicos corresponden a una fecha próxima a la finalización del período de la sequía R1. 
En el primer ensayo (Cuadro 5) la variedad Desirée mostró más susceptibilidad a la sequía temprana $\mathrm{R} 1$ en su rendimiento, altura de planta, número de entrenudos, número de ramas y las otras variables estudiadas. Las variedades Waych'a y Yungay son las menos sensibles en estas variables morfológicas a los efectos de esta sequía. Estas tendencias se mantienen en el ensayo 2 especialmente para las variedades Waych'a y Yungay (Cuadro 6). Por otra parte en el primer ensayo (Cuadro 5), también se observa las variables de la hoja del penúltimo entrenudo (longitud de hoja, longitud de raquis y longitud de peciolo) en las variedades Waych'a y Ch'aska, sufrieron un efecto inverso por efecto de esta sequía y no así en las otras variedades.

En relación a la asociación entre el grado de susceptibilidad al daño por sequía del rendimiento y de variables morfológicas, en ambos ensayos (Cuadros 5 y 6 ) se observa que la susceptibilidad del número de ramas está marcadamente asociada a la susceptibilidad del rendimiento $(r=0.82$ y $r=0.94$ respectivamente). Esto significa que el daño de la sequía en el número de ramas del tallo principal, repercute directamente en el daño del rendimiento de cada variedad de papa. No se puede afirmar lo mismo para las variables número de entrenudos y número de hojas puesto que tuvieron un comportamiento diferenciado en uno y otro ensayo. La susceptibilidad de la Altura de planta definitivamente no está asociada a la susceptibilidad del rendimiento. En el primer ensayo también sobre sale la variable Longitud del penúltimo entrenudo cuya susceptibilidad a la sequía tiene una asociación con la susceptibilidad al rendimiento $(r=0.52)$, por encima de las otras variables de la hoja de este penúltimo entrenudo (longitud de hoja, longitud del raquis y longitud del peciolo).

Susceptibilidad potencial del rendimiento y su correlación con la susceptibilidad de las variables morfológicas al daño por sequía. Para estimar el índice de "Susceptibilidad potencial del rendimiento" se aplicó la siguiente relación: "1 $\mathrm{R} 1 / \mathrm{R} \theta$ ", donde $\mathrm{R} 1$ es el rendimiento de cada variedad en condiciones de sequía y $\mathrm{R} \theta$ es el rendimiento potencial promedio de la población que en el presente estudio se estimó 
sacando el promedio de rendimiento de todas las variedades en condiciones de riego normal. Este rendimiento potencial para el primer ensayo fue de $0.58 \mathrm{~kg} / \mathrm{pl}$ y del segundo ensayo de 0.66 $\mathrm{kg} / \mathrm{pl}$.

El ajuste de la susceptibilidad del rendimiento de cada variedad respecto al rendimiento potencial permite ser más estrictos y realistas a la hora de elegir material genético con tolerancia a la sequía. El material genético con bajo índice de "Susceptibilidad potencial del rendimiento" deberá ser considerado tolerante porque en condiciones de sequía alcanzan rendimientos próximos al rendimiento potencial de la población. Viceversa, el material genético con alto índice de "Susceptibilidad potencial del rendimiento", deberá ser considerado sensible porque en condiciones de sequía alcanzan rendimientos por debajo del rendimiento potencial de la población. Para el primer ensayo las susceptibilidades potenciales fueron: $S$. berthoultii 0.53 , Jaspe 0.14 , Waych'a 0.36, Desirée 0.5, Ch'aska 0.05 y Yungay -0.12 . Para el segundo ensayo fueron: Luk'y 0.48 , Jaspe 0.15 , Waych'a 0.18 , Desirée 0.36 , Ch'aska 0.2 y Yungay 0 . El análisis de correlación muestra a la susceptibilidad del número de ramas $(r=0.5)$ y la susceptibilidad del número de hojas $(r=0.9)$ como las mejor asociadas con las susceptibilidades potenciales del rendimiento de cada variedad. Esto es necesario corroborarlo por las diferencias encontradas en ambos ensayos.

Por lo expuesto, se puede argüir que el material genético de papa cuyo número de ramas y número de hojas del tallo principal estén menos afectados por la sequía, serán aquellos que rindan más en condiciones de este tipo de estrés. Contrariamente, el material genético cuyo número de ramas y número de hojas estén más afectados por la sequía, serán los menos productivos en condiciones de sequía. Este carácter del grado de susceptibilidad a la sequía del número de ramas y del número de hojas del tallo principal, pueden ser usados como indicadores para la elección de material progenitor con tolerancia a este factor, pero será necesario conocer su heredabilidad. 
Tourneux, et al (2003) indican que los parámetros morfológicos y agronómicos están determinados por efectos complejos y en base a proceso de largo plazo y acumulativos, lo que explica porque el rendimiento se asocia mejor con caracteres morfológicos que con caracteres instantáneos como son las mediciones fisiológicas. Ellos encontraron que el Índice de Cosecha (IC) y la biomasa seca total están correlacionadas con el rendimiento total, lo que muestra que el rendimiento fue más afectada por la variación en la distribución de los asimilados hacia los tubérculos (IC) que por la variación de la cantidad total de biomasa seca producida.

Las especies Solanum berthoultii y $S$. juzepczukii (Luk'y) presentaron gran capacidad de adaptación a la sequía, sin embargo, sus rendimientos de tubérculos en condiciones de sequía fueron las más bajas. Los genotipos tolerantes a estreses abióticos, tales como helada y sequía, gastan la mayor parte de su energía resistiendo al estrés en detrimento de la producción de tubérculos. Para un proceso de selección de genotipos superiores, es importante buscar el equilibrio entre la resistencia al estrés abiótico y la capacidad de rendir. Los caracteres que determinan alto el potencial de rendimiento del tubérculo no son necesariamente similares a las que determinar la sobrevivencia o la producción de tubérculos en condiciones de estrés (Vacher, 1998).

Las estrategias desarrolladas por la planta para sobrevivir la sequía, ya sea en forma individual o como generaciones sucesivas, es probable que difiera como un resultado de las diferentes dificultades que la planta haya encontrado en su medio ambiente a través del tiempo evolutivo (Valladares, 2004).

\section{Asociación entre la susceptibilidad a la sequía de variables morfológicas}

Los Cuadros 7 y 8 muestran el análisis de correlación entre la susceptibilidad al daño por sequía de diferentes variables morfológicas para los dos ensayos respectivamente. 
Cuadro 7. Correlación ( $r$ ) entre el grado de susceptibilidad al daño por sequía (1-R1/R0) de diferentes variables morfológicas. Primer ensayo.

\begin{tabular}{|c|c|c|c|c|c|c|c|c|c|}
\hline & Rend. & $\begin{array}{l}\text { Altura de } \\
\text { planta }\end{array}$ & $\begin{array}{l}\text { Número de } \\
\text { entrenudos }\end{array}$ & $\begin{array}{l}\text { Número } \\
\text { de hojas }\end{array}$ & \begin{tabular}{|c|} 
Número \\
de \\
ramas
\end{tabular} & $\begin{array}{c}\text { Long. del } \\
\text { Penúltimo } \\
\text { Entrenudo (PE) }\end{array}$ & $\begin{array}{l}\text { Longitud } \\
\text { de hoja } \\
\text { del PE }\end{array}$ & $\begin{array}{l}\text { Longitud de } \\
\text { raquis de la } \\
\text { hoja del PE }\end{array}$ & $\begin{array}{l}\text { Longitud de } \\
\text { peciolo de la } \\
\text { hoja del PE }\end{array}$ \\
\hline Rend. & 1 & & & & & & & & \\
\hline A. Planta & 0.31 & 1 & & & & & & & \\
\hline N. Entren & 0.58 & 0.84 & 1 & & & & & & \\
\hline N. Hojas & 0.00 & 0.85 & 0.76 & 1 & & & & & \\
\hline \begin{tabular}{|l|} 
N. \\
Ramas
\end{tabular} & 0.82 & 0.78 & 0.86 & 0.47 & 1 & & & & \\
\hline LPE & 0.52 & 0.87 & 0.68 & 0.50 & 0.86 & 1 & & & \\
\hline LHPE & 0.42 & -0.49 & -0.73 & -0.54 & -0.41 & -0.15 & 1 & & \\
\hline LRPE & 0.36 & -0.46 & -0.70 & -0.49 & -0.37 & -0.16 & 0.98 & 1 & \\
\hline LPPE & 0.08 & -0.04 & -0.50 & -0.18 & -0.04 & 0.33 & 0.87 & 0.88 & 1 \\
\hline
\end{tabular}

Nivel de significación $5 \%$,

R0 = Riego normal a capacidad de campo (testigo)

R1 = Sequía al inicio de la tuberización de cada variedad.

Los datos de los parámetros morfológicos corresponden a una fecha próxima a la finalización del período de la sequía R1. 
Cuadro 8. Correlación ( $r$ ) entre el grado de susceptibilidad al daño por sequía (1-R1/R0) de diferentes variables morfológicas. Segundo ensayo.

\begin{tabular}{|c|c|c|c|c|c|}
\hline & Rendimiento & $\begin{array}{c}\text { Altura de } \\
\text { planta }\end{array}$ & $\begin{array}{l}\text { Número de } \\
\text { entrenudos }\end{array}$ & $\begin{array}{c}\text { Número de } \\
\text { hojas }\end{array}$ & $\begin{array}{c}\text { Número de } \\
\text { ramas }\end{array}$ \\
\hline Rendimiento & 1 & & & & \\
\hline Altura planta & -0.03 & 1 & & & \\
\hline $\begin{array}{l}\text { Número } \\
\text { entrenudos }\end{array}$ & -0.39 & 0.47 & 1 & & \\
\hline Número hojas & 0.67 & 0.49 & -0.28 & 1 & \\
\hline Número ramas & 0.95 & -0.13 & -0.23 & 0.44 & 1 \\
\hline
\end{tabular}

Nivel de significación $5 \%$

R0 = Riego normal a capacidad de campo (testigo)

R1 = Sequía al inicio de la tuberización de la variedad Waych'a (Variedad testigo).

Los datos de los parámetros morfológicos corresponden a una fecha próxima a la finalización del período de la sequía R1. 
En relación a la asociación entre el grado de susceptibilidad a la sequia de las variables morfológicas estudiadas en el primer ensayo (Cuadros 7) se observa que la susceptibilidad de la altura de planta esta marcadamente asociada con la susceptibilidad del número de entrenudos, número de hojas, número de ramas y la longitud del penúltimo entrenudo. Este comportamiento se repite en el segundo ensayo (Cuadro 8) pero con menos grado de asociación. Por su parte en el Cuadro 7 también se observa que el número de entrenudos esta marcadamente asociada con el número de hojas, número de ramas, longitud del penúltimo entrenudo e inversamente asociada con la longitud de hoja del penúltimo entrenudo $(r=-$ 73) y la longitud de raquis del penúltimo entrenudo $(r=-70)$.

\section{Conclusiones}

La sequía altera más fuertemente las características morfológicas de las variedades de papa cuando esta ocurre en etapas iniciarles del crecimiento de la planta. Es por esto que en ambos ensayos se observó un mayor efecto en la morfología de la planta por la sequía temprana (R1) que por la sequía tardía (R2).

En la mayoría de las variedades la altura de planta, el número de entrenudos, el número de hojas y el número de ramas fueron las variables morfológicas más afectadas por la sequía temprana (R1). La mayor velocidad de crecimiento de la variedad Waych'a le permitió evadir este efecto.

La sintomatología de hojas y tallos por efecto de la sequía temprana (R1) expresada a través de la variable "índice de daño" a estos órganos de la planta, muestra a las Variedades Ch'aska y Luk'y como las que expresaron en menor medida el efecto de la sequía. La variedad Waych'a si bien presenta un mayor índice de daño en sus hojas y tallos, también presenta una mayor capacidad de recuperación luego del riego de recuperación. 
El alto índice de raíz (biomasa radicular/biomasa foliar) por efecto de la sequía temprana (R1) en la variedad Waych'a, muestra su gran capacidad para incrementar su biomasa radical en condiciones de sequía, aspecto que estaría contribuyendo a su parcial tolerancia a la sequía. Las otras variedades no alteraron su índice de raíz por efecto de la sequía. Por otra parte, el índice de cosecha tampoco fue afectado por la sequía en ninguna de las variedades estudiadas, aspecto corroborado por estudios anteriores.

La sequía temprana (R1) promovió la producción de tubérculos de menor tamaño $\left(4^{\mathrm{a}}\right.$ y $\left.5^{\mathrm{a}}\right)$ como una respuesta natural a la sobrevivencia del cultivo. En la variedad Waych'a, la sequía tardía (R2) indujo a la formación de tubérculos de tamaño $2^{\mathrm{a}}$ y $3^{\mathrm{a}}$, aspecto que muestra su capacidad para minimizar el efecto de esta sequía llenado más aceleradamente sus tubérculos pequeños.

La variedades Waych'a y Yungay son las menos sensibles a la sequía temprana (R1) en su rendimiento, altura de planta, número de entrenudos, número de ramas y las otras variables estudiadas y Desirée es la más sensible.

La susceptibilidad a la sequía del número de ramas está marcadamente asociada a la susceptibilidad del rendimiento $(r=$ 0.82 y $r=0.94$ para los dos ensayos respectivamente). Esto significa que el daño de la sequía en el número de ramas del tallo principal, repercute directamente en el daño del rendimiento de cualquier variedad de papa. No se puede afirmar lo mismo para las variables número de entrenudos y número de hojas puesto que tuvieron un comportamiento diferenciado en uno y otro ensayo.

La susceptibilidad de la Altura de planta definitivamente no está asociada a la susceptibilidad del rendimiento. En el primer ensayo también sobre sale la variable Longitud del penúltimo entrenudo cuya susceptibilidad a la sequía tiene una asociación con la susceptibilidad al rendimiento de $r=0.52$, por encima de las otras variables de la hoja de este penúltimo entrenudo (longitud de hoja, longitud del raquis y longitud del peciolo). 
Un criterio para ser más estrictos y realistas a la hora de elegir material genético con tolerancia a la sequía en su productividad, es estimar el índice de "Susceptibilidad potencial del rendimiento" calculado a partir del rendimiento potencial de las variedades. Yungay, Ch'aska, Waych'a y Jaspe fueron las menos sensibles a la sequia respecto a $S$. berthoultii, Luk'y y Desirée que fueron las más sensibles en su productividad. La susceptibilidad del número de ramas y del número de hojas del tallo principal parecen estar asociadas con la Susceptibilidad potencial del rendimiento, pero es necesario corroborarlo por las diferencias encontradas en ambos ensayos.

Las especies Solanum berthoultii y $S$. juzepczukii (Luk'y) presentaron gran capacidad de adaptación a la sequía, sin embargo, sus rendimientos en condiciones de sequía fueron las más bajas. Este tipo de material genético que se caracteriza por su tolerancia a estreses abióticos, gastan la mayor parte de su energía resistiendo al estrés en detrimento de la producción de tubérculos.

En condiciones normales de humedad en el suelo, en todas las variedades no se pudo demostrar que exista una clara asociación de los parámetros morfológicos evaluados con el rendimiento.

Por otra parte, las variedades menos sensibles a la sequía en su rendimiento que fueron identificadas en el presente estudio (Yungay, Jaspe y Waych'a), si bien presentan características morfológicas similares, es posible que difieran en sus mecanismos para tolerar la sequía, las cuales no fueron consideradas en el presente estudio, pero es necesario destacar las características de la variedad Waych'a, cuyo comportamiento en general difiere de las otras variedades. Su mayor velocidad de crecimiento, el aumento de su índice de raíz, su capacidad de recuperación después del riego y el llenado de sus tubérculos pequeños en condiciones de sequía, entre otras, son posiblemente estrategias particulares de esta variedad que la hacen menos sensible y con mayor estabilidad en condiciones de estrés. 


\section{Literatura citada}

Alarcón, C. (1976). Determinación y descripción de cultivares nativos de papa. Tesis Ing. Agr., Universidad Mayor de San Simón, Cochabamba, Bolivia.

Staubi, B., Wenger, R., Wymann, S. 2008. La Papa y el cambio climático. Inforesources. Focus $n^{0} 1 / 08$.

Calispa, F. (2000). Manejo y conservación de suelos. Consorcio de capacitación para el manejo de recursos Naturales. Quito, Ecuador, pp 169-170.

Coppock, D.L. y Valdivia, C (editores). 2001 Sustaining agropastoralism on the Bolivian Altiplano: The Case of San José Llanga. Logan, Utah: Utah State University, Department of Rangeland Resources.

Deblonde P.M.K., Ledent J.F. (2001). Effects of moderate drought conditions on green leaf number, stem height, leaf length and tuber yield of potato cultivars, Eur. J. Agron. 14 (2001) 31-41.

Haverkort, A. J., Uenk, D., Veroude, H. and Van de Waart, M. (1991) Relationships between ground cover, intercepted solar radiation, leaf area index and infrared reflectance of potato crops. Potato Res., 34, 113-121.

Jefferies R.A. (1992). Effects of drought on chlorophyll fluorescence in potato (Solanum tuberosum L.). II. Relations between plant growth and measurements of fluorescence, Potato Res. 35. 35-40.

Jensen, N. 2010 Exploring the relationships between livelihood dimensions and socio-ecological resilience in the Bolivian Altiplano. Master's Thesis, University of Missouri-Columbia.

Mackerron D.K.L., Jefferies R.A. (1996). The influence of early moisture stress on tuber numbers in potato, Potato Res. 29. pp 299-321. 
Martinez, C.A. and Moreno U. (1992). Expresiones fisiológicas a la sequía en dos variedades e papa sometidas a estrés hídrico en condiciones de campo. Revista Brasilera de Fisiología Vegetal 4(1):33-38.

Piñas, J. 2012. Riego. Monografía. Universidad nacional de Huancavelica. Acobamba. Perú.

Potters, G., T.P. Pasternak, Y. Guisez, K.J. Palme y M.A.K. Jansen. 2007. Stress-induced morphogenic responses: growing out of trouble? Trends Plant Sci. 12(3), 99-105.

PROINPA (1994). Compendio del Programa de Investigación de la Papa, Cochabamba, Bolivia. 35 p.

Tourneux, C; Devaux, A; Camacho, M.R.; Mamani, P.; Ledent, J.F. (2003). Effects of water shortage on six potato genotypes in the highlands of Bolivia (I): Morphological parameters, growth and yield. Agronomie 23 (2003) 169-179 169. INRA, EDP Sciences. DOI: 10.1051/agro:2002079.

Shao, H.B., L.Y. Chu, C.A. Jaleel y C.X. Zhao. 2008. Waterdeficit stress-induced anatomical changes in higher plants. C.R. Biol. 331, 215-225.

Spitters C.J.T., Schapendonk A.H.C.M. (1990). Evaluation of breeding strategies for drought tolerance in potato by means of crop growth simulation, Plant and Soil 123. pp 193-203.

Vacher, JJ (1998). Responses of two main Andean crops, quinoa (Chenopodium quinoa Willd) and papa amarga (Solanum juzepczukii Buk.) to drought on the Bolivian Alptiplano: Significance of local adaptation. In Agriculture Ecosystems \& Environment, 68, 99-108.

Valladares, F. 2004. Ecología del bosque mediterráneo en un mundo cambiante. Pp. 163-190. Ministerio de Medio Ambiente, EGRAF, S. A., Madrid. ISBN: 84-8014-552-8. 
Zeballos, H; Balderrama, F; Condori, B; Blajos, J. 2009.

Economía de la Papa en Bolivia (1998 - 2007). Fundación PROINPA, Cochabamba, Bolivia. 